\title{
Evidence for Asian dust effects from aerosol plume measurements during INTEX-B 2006 near Whistler, BC
}

\author{
W. R. Leaitch ${ }^{1}$, A. M. Macdonald ${ }^{1}$, K. G. Anlauf ${ }^{1}$, P. S. K. Liu ${ }^{1}$, D. Toom-Sauntry ${ }^{1}$, S.-M. Li ${ }^{1}$, J. Liggio ${ }^{1}$, K. Hayden ${ }^{1}$, \\ M. A. Wasey ${ }^{1}$, L. M. Russell ${ }^{2}$, S. Takahama ${ }^{2}$, S. Liu ${ }^{2}$, A. van Donkelaar ${ }^{3}$, T. Duck ${ }^{3}$, R. V. Martin ${ }^{3}$, Q. Zhang ${ }^{4}$, Y. Sun ${ }^{4}$, \\ I. McKendry ${ }^{5}$, N. C. Shantz ${ }^{6}$, and M. Cubison ${ }^{7}$ \\ ${ }^{1}$ Science and Technology Branch, Environment Canada, Toronto, Ontario, M3H 5T4, Canada \\ ${ }^{2}$ Scripps Institute of Oceanography, University of California, San Diego, 92093, USA \\ ${ }^{3}$ Department of Physics and Atmospheric Science, Dalhousie University, Halifax, NS M3J 1P3, Canada \\ ${ }^{4}$ State University of New York at Albany, Albany, New York, USA \\ ${ }^{5}$ University of British Columbia, Vancouver, BC, V6T 1Z2, Canada \\ ${ }^{6}$ Department of Chemistry, University of Toronto, Ontario, Canada \\ ${ }^{7}$ University of Colorado, Boulder, Colorado, USA
}

Received: 27 August 2008 - Published in Atmos. Chem. Phys. Discuss.: 28 October 2008

Revised: 11 May 2009 - Accepted: 11 May 2009 - Published: 3 June 2009

\begin{abstract}
Several cases of aerosol plumes resulting from trans-Pacific transport were observed between $2 \mathrm{~km}$ and $5.3 \mathrm{~km}$ at Whistler, BC from 22 April 2006 to 15 May 2006. The fine particle $(<1 \mu \mathrm{m})$ chemical composition of most of the plumes was dominated by sulphate that ranged from $1-5 \mu \mathrm{g} \mathrm{m}^{-3}$ as measured with a Quadrapole Aerosol Mass Spectrometer (Q-AMS). Coarse particles $(>1 \mu \mathrm{m})$ were enhanced in all sulphate plumes. Fine particle organic mass concentrations were relatively low in most plumes and were nominally anti-correlated with the increases in the number concentrations of coarse particles. The ion chemistry of coarse particles sampled at Whistler Peak was dominated by calcium, sodium, nitrate, sulphate and formate. Scanning transmission X-ray microscopy of coarse particles sampled from the NCAR C-130 aircraft relatively close to Whistler indicated carbonate, potassium and organic functional groups, in particular the carboxyl group. Asian plumes reaching Whistler, BC during the INTEX-B study were not only significantly reduced of fine particle organic material, but organic compounds were attached to coarse particles in significant quantities. Suspension of dust with deposited organic material and scavenging of organic materials by dust near anthropogenic sources are suggested, and if any secondary organic aerosol (SOA) was formed during transport from Asian source regions across the Pacific it was princi-
\end{abstract}

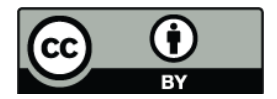

Correspondence to: W. R. Leaitch (Richard.Leaitch@ec.gc.ca) pally associated with the coarse particles. An average of profiles indicates that trans-Pacific transport between 2 and $5 \mathrm{~km}$ during this period increased ozone by about $10 \mathrm{ppbv}$ and fine particle sulphate by $0.2-0.5 \mu \mathrm{g} \mathrm{m}^{-3}$. The mean sizes of the fine particles in the sulphate plumes were larger when dust particles were present and smaller when the fine particle organic mass concentration was larger and dust was absent. The coarse particles of dust act to accumulate sulphate, nitrate and organic material in larger particles, diminishing the role of these compounds in indirect radiative forcing, but potentially enhancing their roles in direct radiative forcing.

\section{Introduction}

The transport of trace gases and particles at the intercontinental scale is a concern for atmospheric chemistry, climate forcing and the national regulation of air pollutants. It is of particular importance to understand the impacts of Asia on other parts of the Northern Hemisphere (NH) because of the rapid growth in that region (Streets and Waldhoff, 2000) and because wind over desert regions of Asia are a significant source of dust to the springtime NH (e.g. Uematsu et al., 1983; Zhao et al., 2006). The transport of dust and pollution from Asia to North America has been the subject of a number of observational investigations (e.g. Uematsu et al., 1983; Andreae et al., 1985; Parungo et al., 1986; Jaffe et al., 1999, 2003; Husar et al., 2001; McKendry, 2001; Clarke et

Published by Copernicus Publications on behalf of the European Geosciences Union. 


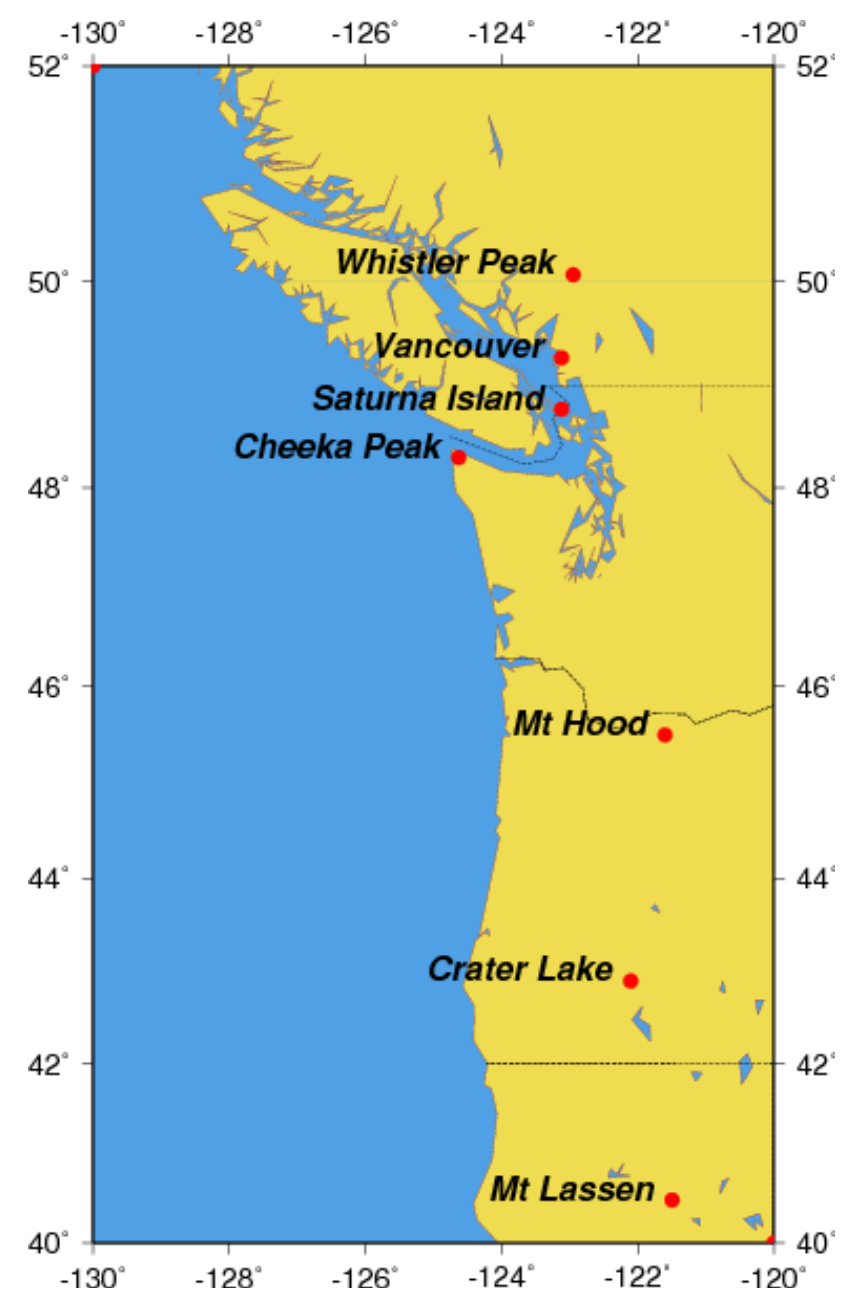

Fig. 1. Map for Whistler, BC, Canada and much of the area covered by the C-130 (from McKendry et al., 2008).

al., 2001; Huebert et al., 2003; Prospero et al., 2003; Brock et al., 2004). These studies indicate that the main transport of Asian aerosol to North America occurs during the spring and, despite different regional sources, dust and sulphate are often but not always coincident in the plumes. Some of the sulphate may result from aqueous-phase processing during transport (e.g. Brock et al., 2004). These plumes also have been found to contain pesticides, such as hexachlorocyclohexane (Harner et al., 2005) and mercury (Seigneur et al., 2004; Jaffe et al., 2005; Pan et al., 2007; Weiss-Penzias, 2007). Modelling studies have identified pathways, transport times and potential impacts on North American air quality (e.g. Walker et al., 2008; van Donkelaar et al., 2008; Zhao et al., 2006; Gong et al, 2006; Heald et al., 2006; Holzer et al. 2003, 2005; Jacob et al. 1999; Song and Carmichael, 1999). Much of the transport occurs above $2 \mathrm{~km}$ as the aerosol near the source is lifted relatively quickly, and at the west coast of North America, subsidence and mountain flows help to bring the plumes nearer the surface (e.g. McKendry et al., 2001;
McKendry et al., 2008). Still, much of the plume remains aloft as it crosses North America (e.g. van Donkelaar et al., 2008). Transport between Asia and western North America during the springtime typically takes $6-10$ days (Stohl et al., 2002; Holzer et al., 2003) and increases sulphate levels over the west coast of North America by up to $1.5 \mu \mathrm{g} \mathrm{m}^{-3}$ (e.g. van Donkelaar et al., 2008; Heald et al.). Ozone in springtime air arriving from Asia is increased by $5-10$ ppbv (e.g. Zhang et al., 2008; Jacob et al., 1999). The fact that much of the Asian aerosol that reaches across the Pacific remains aloft enhances its ability to impact both atmospheric chemistry and radiative forcing of the atmosphere as gases and particles lofted into the middle and upper troposphere have longer lifetimes (e.g. Rasch et al., 2000).

As part of the INTEX-B experiment (Singh et al., 2009), two sets of measurements were made at Whistler, British Columbia (Fig. 1) from 22 April 2006 to 17 May 2006. Vertical profiles of aerosol chemistry and microphysics, $\mathrm{CO}$ and $\mathrm{O}_{3}$ were conducted between about 1000 and $5300 \mathrm{~m}$ above mean sea level (MSL) and continuous observations were made at Whistler Peak (2182 m-MSL). The continuous observations at the Peak site were part of an on-going measurement program (Macdonald et al., 2006) that were augmented, as described below, for the INTEX-B period. The main objectives of the observations at Whistler during INTEX-B were to:

- provide improved context for the on-going measurements at the peak of Whistler Mountain,

- quantify trans-Pacific transport,

- identify the key transport pathways and mechanisms that deliver aerosols to North America,

- provide more characterizations of the aerosol in plumes reaching over the west coast of North America.

A comparison of the aerosol measurements from the aircraft with those conducted at the Peak (a study of the fine particle composition at Whistler Peak during INTEX-B is described by Sun et al., 2009) is used to provide context for the two sets of ambient measurements. The characterization of the fine and coarse particle aerosol obtained from the profile data, the data from the Peak, and single-particle samples collected on the National Center for Atmospheric Research (NCAR) C-130 are used to examine the possible origins and mechanisms of processing of the trans-Pacific aerosol, and how Asian dust may affect transported sulphate and organic compounds. Implications for the impact of this aerosol on climate forcing are suggested. 


\section{Experimental}

\subsection{Whistler Peak}

At the time of INTEX-B, the ongoing measurements at Whistler Peak were $\mathrm{O}_{3}, \mathrm{CO}$, particle chemistry (one-to-two day averaged filters cut at $2.5 \mu \mathrm{m}$ and analyzed by ion chromatography or IC), particle size distributions $(0.01-20 \mu \mathrm{m})$, light scattering and light absorption. Details of the measurements are described by Macdonald et al. (2006).

During the INTEX-B period, the aerosol chemical measurements were enhanced by the addition of a HighResolution Time-of-Flight Aerosol Mass Spectrometer (HRTOF-AMS) and 24-h averaged size segregated samples that were analyzed by IC for ions of chloride, nitrate, sulphate, oxalate, acetate, formate, sodium, ammonium, potassium, magnesium and calcium; carbonate was not measured. The size segregation was done using non-rotating MOUDI samplers reduced to three size cuts $(<1 \mu \mathrm{m}, 1-3 \mu \mathrm{m}$ and $>3 \mu \mathrm{m})$. The MOUDI samplers were mounted outside of the building where the HR-TOF-AMS was housed. The results of the HR-TOF-AMS observations are discussed by Sun et al. (2009), and used here only for comparison with the Cessna Q-AMS. The size segregated observations are discussed here.

\subsection{Airborne observations at Whistler}

Aerosol and trace gas observations were made on a total of 31 project flights conducted from 22 April to 17 May 2006 at Whistler, BC. The platform was an unpressurized Cessna 207 aircraft operated at an airspeed of ca. $50 \mathrm{~m} \mathrm{~s}^{-1}$. The main measurements were $\mathrm{O}_{3}$ (TECO 49), $\mathrm{CO}$ (Aerolaser), particle physical size distribution (PCASP, FSSP300), particle chemistry at one-minute intervals (Quadrapole-Aerosol Mass Spectrometer or Q-AMS), light scattering (Radiance nephelometer) and flight integrated inorganic mass concentrations (single teflon filter analysed by IC). The aircraft was based at Pemberton, $\mathrm{BC}$ about $40 \mathrm{~km}$ north of Whistler. The flights were approximately two hours long and typically consisted of flying to Whistler, profiling up from about $1000 \mathrm{~m}$ to about $5300 \mathrm{~m}$, down again and returning to Pemberton; Whistler Village is at an elevation of $620 \mathrm{~m}$.

Of the 31 flights, 22 are included in this analysis. The remaining flights are not included either because they were conducted in other locations (three flights were used for an intercomparison near Victoria, BC) or because of instrument problems. Valid AMS data were collected on 21 flights; on the other flights radio frequency interference affected the mass spectra, a problem that was intermittent and the origin was not uncovered until May 13. Problems with the pump for the $\mathrm{CO}$ instrument and then with the data file structure resulted in poor data recovery of the $\mathrm{CO}$. The recovery of other measurements, including ozone, was complete throughout the study with the exception of a problem with the PCASP probe that affected sizing, not number concentration, on the first two flights only. Profile data were collected every second, except for the Q-AMS data that were averaged every one minute.

Aerosol instruments inboard of the aircraft sampled the aerosol from an open ended $0.95 \mathrm{~cm}$ OD stainless steel tube. The tube was supported outside of the aircraft and elevated about $0.5 \mathrm{~m}$ from the top of the fuselage. Ram pressure from the aircraft pushed the aerosol into and through the tubing; the end of the tubing was open to the cabin. Approximately $201 \mathrm{~m}^{-1}$ of air was sampled off the tubing by the various aerosol instruments and the remaining aerosol exhausted into the cabin. The maximum length of tubing to any instrument was $2 \mathrm{~m}$, and the residence time in the tubing was $<1 \mathrm{~s}$. As ambient air did flow into the cabin, from various openings in the aircraft as well as from the exhaust of the intake tube, the temperature in the cabin was only slightly warmer than ambient. It is suspected that the aerosol entering the AMS was not significantly dried from its ambient state. Only fine particle measurements were made with inboard instrumentation sampling off the inlet.

Ozone was measured by a Model 49 UV photometric ozone analyzer from Thermo Environmental Instruments Inc. It operated on a 5 second cycle time and was pressure and temperature compensated. Calibrations were performed before and after the field study by means of a NIST traceable ozone calibrator; precision was 1 ppbv and accuracy was \pm 2 ppbv. In-flight zeroes were done for several minutes once or twice each flight by passing ambient air through a Koby air purifier cartridge. Carbon monoxide was measured using an Aerolaser AL5002 instrument based on vacuum-UV resonance fluorescence, and data were recorded every second. This instrument was calibrated and zeroed each flight with a precision of $<2 \mathrm{ppb}$ and accuracy to within about $5 \mathrm{ppb}$; the response time was $<1 \mathrm{~s}$. Unfortunately, problems with the CO pump and with the $\mathrm{CO}$ file system significantly limited data recovery.

Aerosol particle number concentrations and size distributions were measured using a PMS 7610 Condensation Particle Counter (CPC), a PMS PCASP100X, and a PMS FSSP300. The CPC was mounted inboard the aircraft and used to measure the total number concentration of particles $>0.015 \mu \mathrm{m}$ diameter; the threshold size is based on past measurements in the laboratory. The PCASP and FSSP300 were mounted under a wing of the aircraft, and they were used to measure particles in the size ranges of $0.12-3 \mu \mathrm{m}$ and $0.3-20 \mu \mathrm{m}$ respectively. Particles are sampled intrusively into the PCASP resulting in a relatively dry aerosol, whereas sampling with the FSSP300 is done non-intrusively leaving the aerosol in its ambient state at detection (Strapp et al., 1992). The flow rate through the FSSP300 is about $25 \mathrm{~cm}^{3} \mathrm{~s}^{-1}$, which permits a statistically viable sample every second if the number concentration is $\geq$ about $1 \mathrm{~cm}^{-3}$.

The Q-AMS inboard the aircraft sampled particles through a critical orifice and focuses them in an aerodynamic lens. 


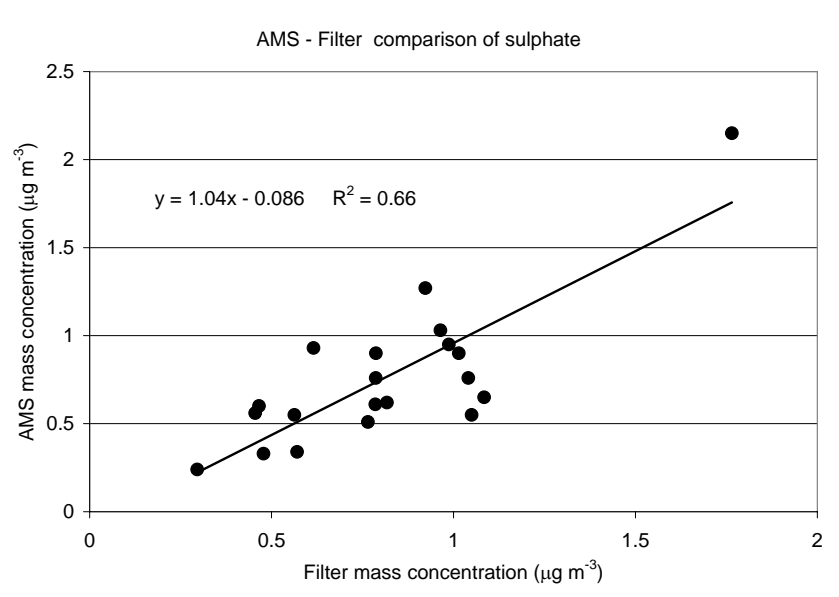

Fig. 2. Comparison of sulphate from filter exposed throughout each flight with sulphate from the Q-AMS onboard the Cessna 207. The aerosol was pulled through a $1 \mu \mathrm{m}$ impactor prior to sampling by the filter.

The particle beam impacts an oven, held at about $550^{\circ} \mathrm{C}$, where the particles are vapourized and ionized by electron impact. The resulting ion fragments are detected with a quadrupole mass spectrometer, and the $m / z$ of the fragments are used to produce mass concentrations of classes of compounds (e.g. sulfate, nitrate, ammonium and total organics). Fundamentals of the Q-AMS are described by Jayne et al. (2000). Other details of data processing and operations can be found in Allan et al. (2003) and Allan et al. (2004). The ionization efficiency, effectively the mass calibration, is determined using known sized particles of ammonium nitrate (AN). Mass calibrations for other components are referenced to that for AN. Particles between about $0.1 \mu \mathrm{m}$ and $0.7 \mu \mathrm{m}$ are efficiently transmitted into the AMS (e.g. Liu et al., 2007). The efficiency with which the particles impacted the oven, stick and volatilize, referred to as the collection efficiency (CE) is discussed below.

Mass concentrations are estimated from the PCASP for comparison with the AMS mass concentrations of fine particles. The PCASP mass estimates are based on the assumption of spherical particles with a specific gravity of $1.5 \mathrm{~g}$ $\mathrm{cm}^{-3}$. The lower size limit of the PCASP $(0.12 \mu \mathrm{m})$ is approximately coincident with the lower limit for which the AMS has 100\% transmission (Liu et al., 2007). Also, except near source regions, the fine particle mass concentration is typically lower for particles smaller than $0.12 \mu \mathrm{m}$, and the uncertainty associated with excluding masses from smaller particles is relatively low. The upper limit $(0.7 \mu \mathrm{m})$ is the approximate upper geometric diameter for which there is $100 \%$ transmission into the AMS (e.g. Liu et al., 2007). All concentrations are referenced to $1 \mathrm{~atm}$ and $25^{\circ} \mathrm{C}$.

\subsection{Collection and analysis of C-130 samples}

During INTEX-B, particles were collected from the NCAR C-130 for functional group analysis (e.g. Russell et al., 2002). The samples were drawn from the main inlet into a rotating impactor (Streaker; PIXE International, Inc.) at $1 \mathrm{~L} \mathrm{~m}^{-1}$ where they impacted on silicon nitride windows $\left(\mathrm{Si}_{3} \mathrm{~N}_{4}\right.$; Silson Ltd.). Samples were frozen after collection; during storage and transportation until time of analysis (June 2006, July 2006, February 2007, and August 2007). Sampled grids and windows were analyzed by Scanning Transmission X-Ray Microscopy (STXM) at the Advanced Light Source at Lawrence Berkeley National Laboratories (Berkeley, CA) Beamlines 5.3.2 (Kilcoyne et al., 2006) in a He-filled chamber maintained at $1 \mathrm{~atm}$. The transmission of photons at energy levels between 278 and $320 \mathrm{eV}$ (minimum spatial resolution was $30 \mathrm{~nm}$ ) was measured and converted to optical density, using a protocol described by Russell et al. (2002) and Maria et al. (2004). Further details of the analysis of the INTEX-B samples are given by Takahama et al. (2007) and Takahama et al. (2008).

\subsection{AMS-Filter comparison}

The CE for the AMS can be below one for some types of materials. For example, crystalline ammonium sulphate (AS) produced in the laboratory and sampled with this Q-AMS routinely yields a $\mathrm{CE}$ of about 0.25 , i.e. only $25 \%$ of the input particles are measured, while for ammonium nitrate the CE is close to one and hence its use in mass calibration. A CE of 1.0 for this particular Q-AMS has in most previous instances been found to provide overall the best agreement with other simultaneous observations (Rupakheti et al., 2005; Phinney et al., 2006; Buset et al., 2006). In instances where the fine particle aerosol is dominated by ammonium sulphate, then a lower CE may be necessary for this particular instrument (Buset el al., 2006; Hayden et al., 2008). A recent detailed study of the CE for the Aerodyne Aerosol Mass Spectrometer is described by Matthew et al. (2008). The detection limits for the one-minute averages of sulphate, nitrate and total organics were $0.04 \mu \mathrm{g} \mathrm{m}^{-3}, 0.04 \mu \mathrm{g} \mathrm{m}^{-3}$ and $0.6 \mu \mathrm{g} \mathrm{m}^{-3}$ respectively, based on two times the standard deviations of zero measurements.

The observations from the Q-AMS during this study are evaluated in three ways. One is by comparison of the AMS mass concentrations with the same measured at Whistler Peak during flybys (Sect. 2.5). The second is by comparison of the total mass concentrations from the Q-AMS in the profiles with that estimated from the size distributions (Sect. 3.1 and Fig. 7). The third is through the comparison with sulphate measured on a single filter with a $1 \mu \mathrm{m}$ cut exposed to the same aerosol over an entire flight (ca. two hours). The results of the latter comparison, of the sulphate mass concentrations from the Q-AMS with those measured from the single filter for 20 flights, is shown in Fig. 2. The Q-AMS mass 

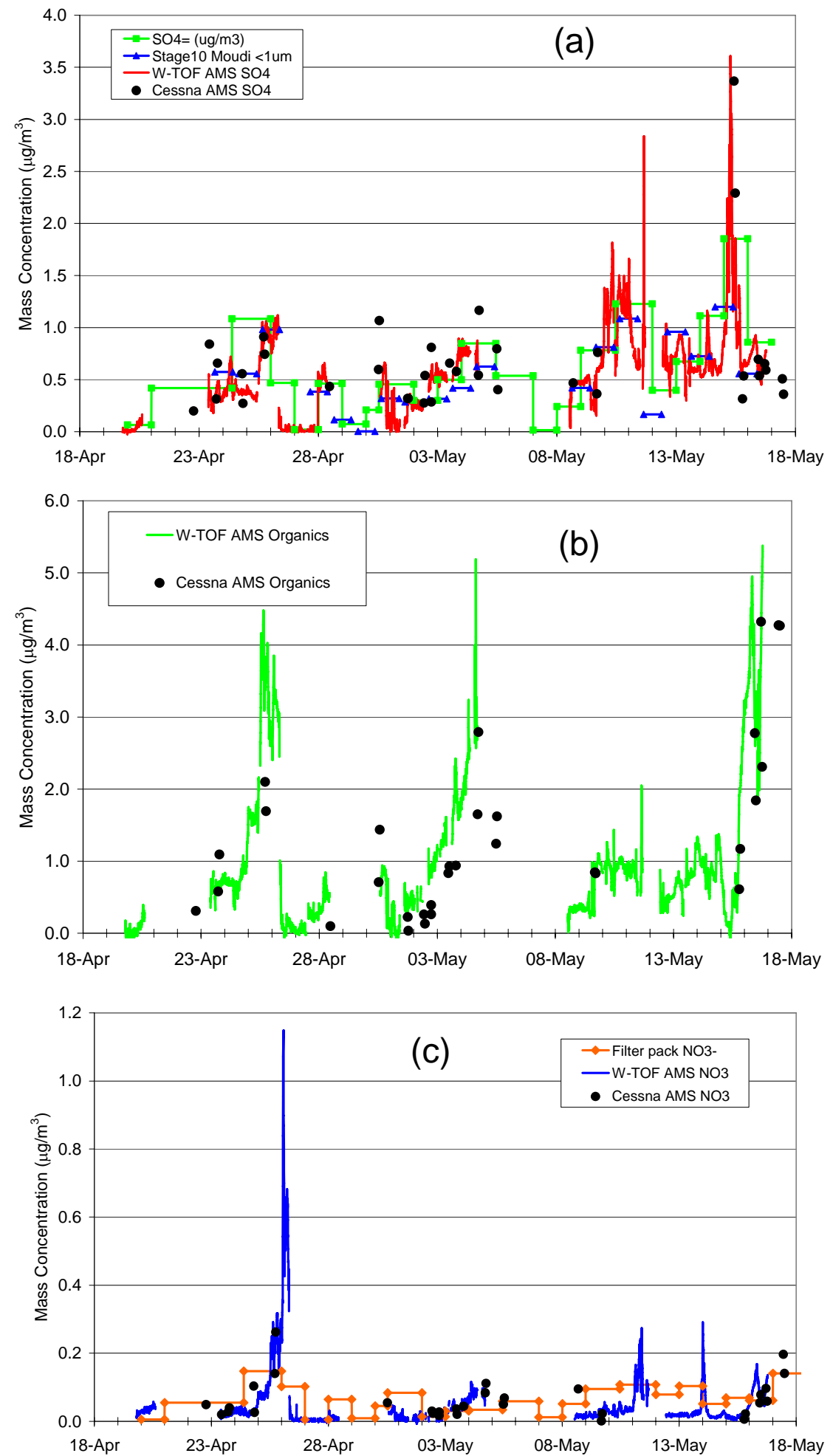

Fig. 3. Comparison of sulphate from aircraft Q-AMS (black dots) with observations at Whistler Peak during the study (a). Sulphate at the peak was measured with the HR-ToF-AMS (red), on Teflon filters behind a $2.5 \mu \mathrm{m}$ cyclone (green) and on Teflon filters in a non-rotating MOUDI impactor (blue). (b) Comparison of organics from aircraft Q-AMS with observations at Whistler Peak during the study. Organics at the peak was measured with the HR-ToF-AMS (green). (c) Comparison of nitrate from Cessna Q-AMS (black dots) with observations at Whistler Peak during the study. Nitrate at the peak was measured with the HR-ToF-AMS (blue) and on Teflon filters behind a $2.5 \mu \mathrm{m}$ cyclone (orange). 
concentrations have been averaged over the same times as the respective filters were exposed and the $\mathrm{CE}$ was assumed to be unity. There is significant scatter in the comparison, but on average the Q-AMS sulphate mass concentrations agree well with the filter results. Q-AMS values can be higher because the Q-AMS data were not always contiguous through a flight; e.g. the Q-AMS data acquisition intermittently shut down due to switching problems. Q-AMS values can be lower than the filter values if a significant fraction of the sulphate is in the $0.7-1 \mu \mathrm{m}$ size range, which is possible here, or if the CE is less than one in any particular instance. With these caveats, there is no indication of a systematic underestimation of the sulphate mass concentrations as measured with the Q-AMS assuming a CE of unity.

\subsection{Comparisons of Cessna and Whistler Peak observa- tions}

Data from the Q-AMS on the Cessna and the three independent measurements of sulphate at the Peak are shown in Fig. 3a. The Cessna values are from the 1-min average QAMS sample closest to the Peak elevation $(2182 \mathrm{~m})$. The Peak sulphate data are from the $2.5 \mu \mathrm{m}$ filters sampled over 1-2 days, the size separated samples for $<1 \mu \mathrm{m}$ diameter, and the HR-ToF-AMS (Sun et al., 2009). The median of the differences between the two AMS' is $23 \%$. Note that the HR-ToF-AMS mass concentrations are based on a CE of 0.5 (Sun et al., 2009), whereas the CE for the Q-AMS, as above, is assumed here to be 1.0. The aerosol entering the building at the Peak was warmed by ca. $15^{\circ} \mathrm{C}$ resulting in a much drier aerosol. Since the Peak aerosol was neutralized or only mildly acidic, with the exception of the sulphate plume during the morning of 15 May, the importance of drying of the aerosol to the CE is increased (e.g. Allan et al., 2004). This may account for some of the difference in the CEs between the two AMS'. Slight differences in the oven geometries might also contribute to the different CE.

The fine particle total organic mass concentrations measured with the Q-AMS on the Cessna near Whistler Peak and with the HR-ToF-AMS at the Peak are shown together in Figure $3 b$. The two organic measurements covary and the median of the differences in the mass concentrations is $42 \%$. During the period 25 April to 4 May the Cessna AMS organic concentrations are about $60-70 \%$ of the Peak measurements; whereas the Cessna sulphate measurements during that same period (Fig. 3a) are slightly higher than those at the Peak. These discrepancies might arise from two sources: the differences in collection efficiency between the instruments and the coarser mass resolution of the Q-AMS relative to the HRToF-AMS.

The median of the differences between the nitrate mass concentrations from the Cessna Q-AMS and the Peak HRToF-AMS is $33 \%$. With the exception of a brief period beginning late on 25 April and ending early on 26 April, nitrate is overall quite low relative to sulphate. Besides the 25-26
April period, two other increases in nitrate are noticeable at the Peak during overnight hours. Much of the fine particle nitrate at Whistler Peak appears to have been associated with organic material (Sun et al., 2009).

In Fig. 4a, the number concentrations of particles $>300 \mathrm{~nm}$ measured from the Cessna PCASP are compared with the one-hour averaged values measured at the Peak using a Grimm OPC; the median of the differences is $13 \%$. The coarse particle $(>1 \mu \mathrm{m})$ number concentrations from the Cessna (10 second averages of the FSSP300) and at the Peak (one hour averages from the Grimm OPC) are compared in Fig. $4 \mathrm{~b}$; the median of the differences is $51 \%$. It is expected that the Cessna coarse particle number concentrations will be biased higher than the peak values. The FSSP300 is a non-intrusive sampling probe, while at the Peak the particles were drawn into the OPC through about $3 \mathrm{~m}$ of tubing and dried via the warming from ambient temperatures to inside temperatures. Inlet losses will bias the concentrations at the Peak to lower values, and water on the particles sampled with the FSSP300 will bias the concentrations from that probe higher. Other differences between the two measurements are expected due to the differences in averaging time (i.e. higher variability across the one hour sampling time could lead to a greater offset of the $10 \mathrm{~s}$ measurement) as well as due to differences in the optical geometries of the FSSP300 and the Grimm OPC. Different optical configurations may yield different responses to the ambient coarse particles.

The median of the differences between the Cessna ozone the Peak ozone is $6 \%$ (Fig. 4c). In this case, drawing comparisons of one hour averages with one second averages is likely a significant factor in the differences.

\section{Observations}

\subsection{Cessna profiles}

The INTEX-B period at Whistler Peak was marked by intervals with the temperature below $0^{\circ} \mathrm{C}$ and the relative humidity (RH) above $90 \%$ alternating with intervals when the temperatures reached above $0^{\circ} \mathrm{C}$ and the $\mathrm{RH}$ went below $60 \%$ (Fig. 5). Diurnal changes were superimposed on this, e.g. during the morning flights Whistler Peak was usually above the top of the mountain convective layer (MCL: de Wekker et al., 2004), and during the afternoon the top of the MCL was often above Whistler Peak.

During the first of the warm periods (23-26 April), back trajectories from the Canadian Meteorological Centre (http:// www.msc-smc.ec.gc.ca/cmc/index_e.html) indicated that the air masses arriving at approximately $3 \mathrm{~km}$ at Whistler had left the coast of Asia about 5-6 days prior to arriving on 22 April and about 7-8 days prior to arriving on 25 April 25. Dust from strong storms over Mongolia impacted Beijing, China from about 15-20 April 2006 (e.g. Papayannis et al., 

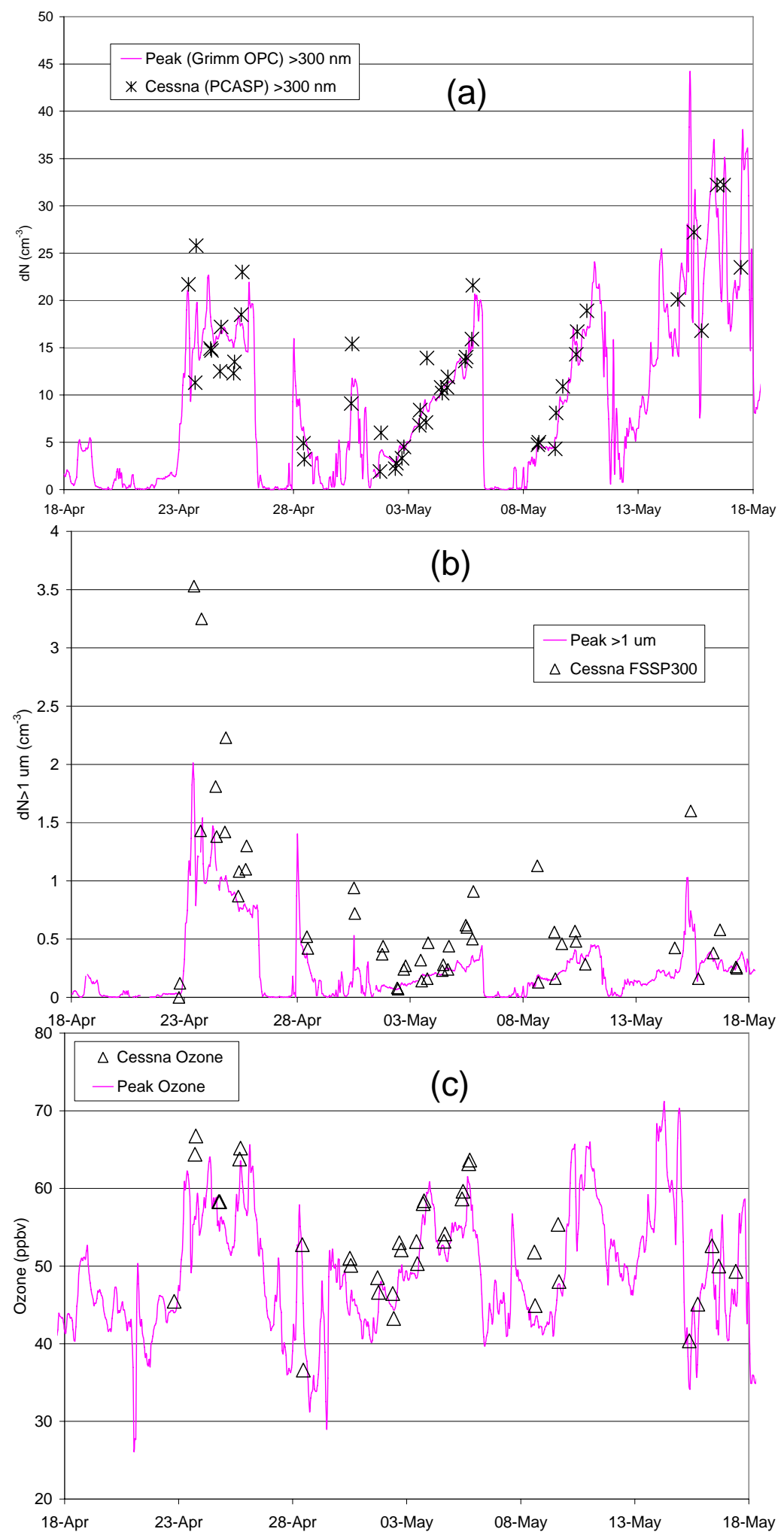

Fig. 4. (a) Comparison of the number concentrations of particles $>300 \mathrm{~nm}$ measured with the PMS PCASP on the Cessna (black crosses) with the observations of particle number concentrations $>300 \mathrm{~nm}$ from the OPC at Whistler Peak. (b) Comparison of the number concentrations of coarse particles $(>1 \mathrm{~mm}$ ) from the PMS FSSP300 on the Cessna (black triangles) and from the OPC at Whistler Peak. (c) Comparison of ozone measured on the Cessna (black triangles) with ozone measured at Whistler Peak. 


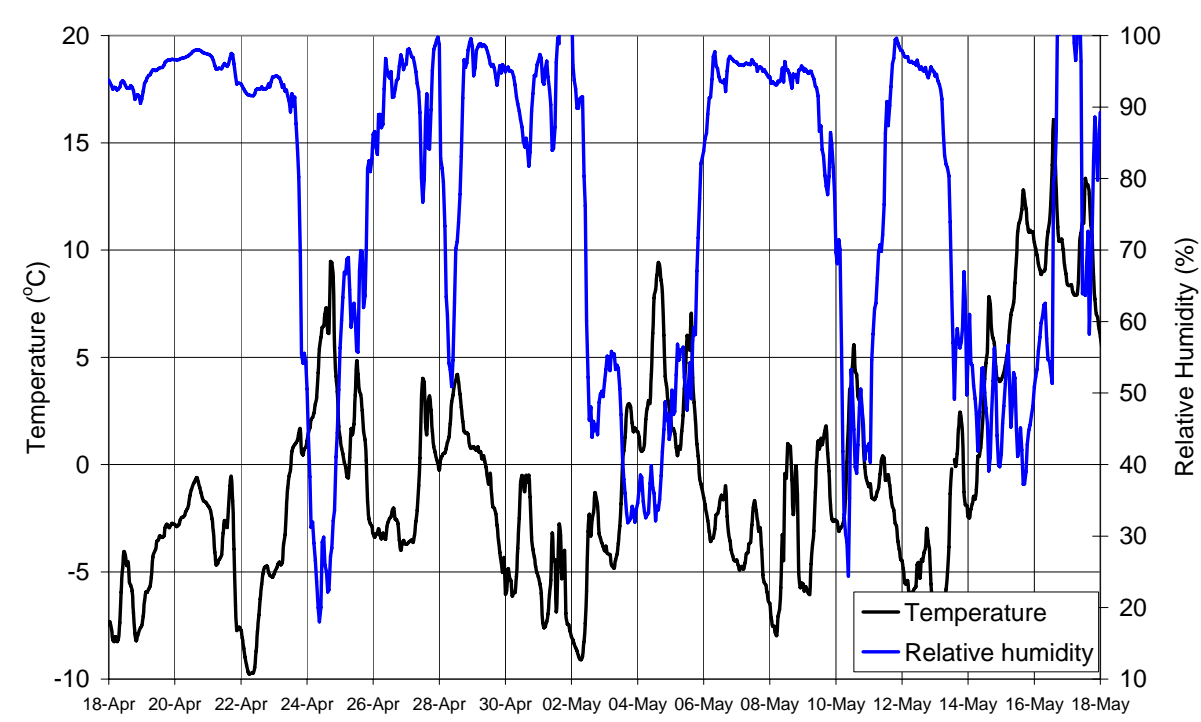

Fig. 5. Time series of temperature and relative humidity $(\mathrm{RH})$ at Whistler Peak.
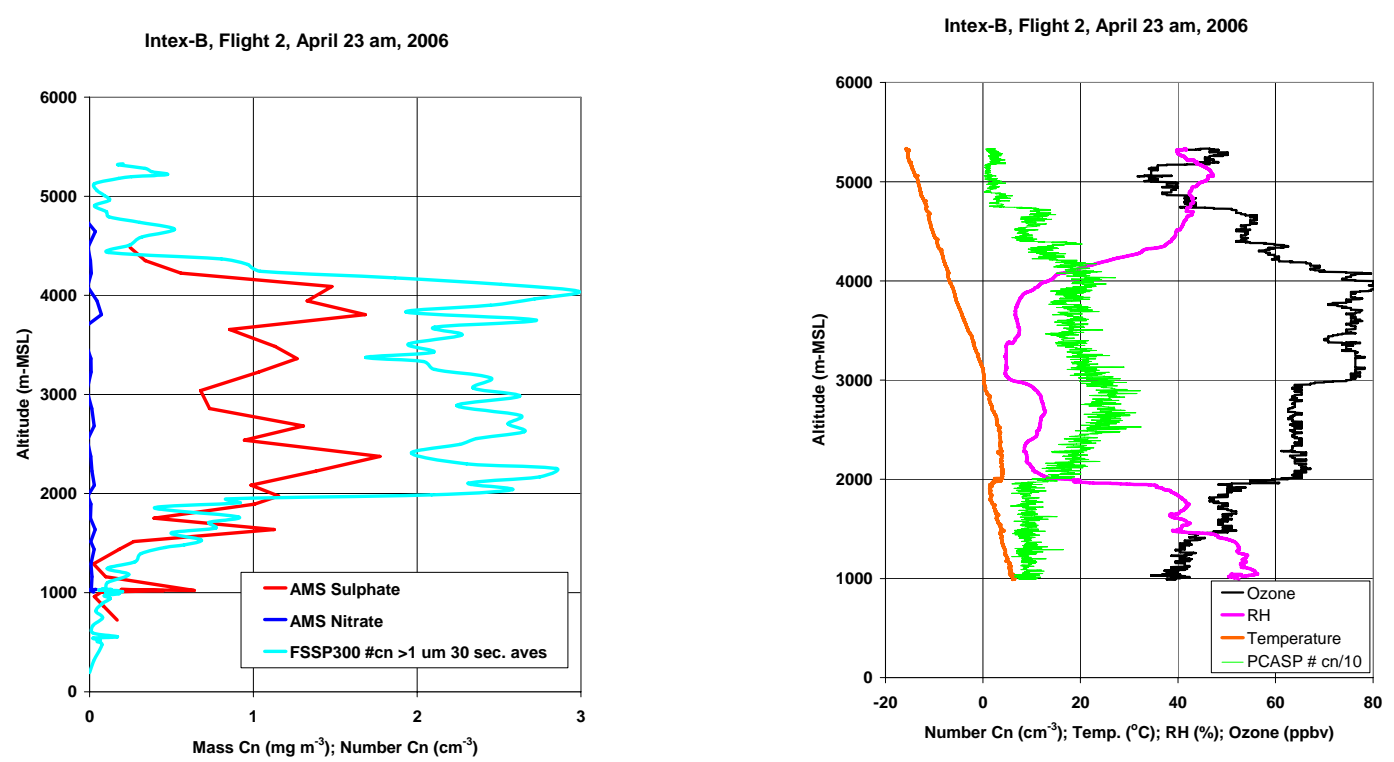

Fig. 6. Vertical profile data from the morning of 23 April 2006 at Whistler, BC. The left hand plot shows the mass concentrations of nitrate and sulphate measured with the AMS. The right hand plot shows the number concentrations of particles measured with the PCASP (divided by 10), particles $>1 \mu \mathrm{m}$ measured with the FSSP300, ozone, relative humidity (RH) and temperature.

2007), and Mongolian dust also transported across the Pacific reaching the Whistler area (e.g. McKendry et al., 2008).

Flights were conducted during the afternoon of 22 April and during the morning and afternoon of each of 23, 24 and 25 April. Profile data from the flight during the morning of 23 April (flight 2) are plotted in Figure 6. Shown in the left hand panel are mass concentrations of sulphate and nitrate from the Q-AMS and the number concentrations of particles $>1 \mu \mathrm{m}$ diameter (coarse particles) measured with the FSSP300. Organics were not quantifiable from this flight due to broadening of the mass spectra. Shown in the right hand panel are temperature, relative humidity $(\mathrm{RH})$, ozone and the number concentrations of particles $>0.12 \mu \mathrm{m}$ measured with the PCASP. Profile data from the afternoon of 23 April (flight 3) and the afternoon of 25 April (flight 7) are shown in Figs. 7a, 8a and 8b, 7b, respectively. Each panel in Fig. 7 shows the mass concentrations measured with the AMS (total mass is the sum of sulphate, nitrate, ammonium and organics), the mass estimated from the PCASP for the size range of $0.12-0.7 \mu \mathrm{m}$ (Sect. 2), and the number concentrations of 

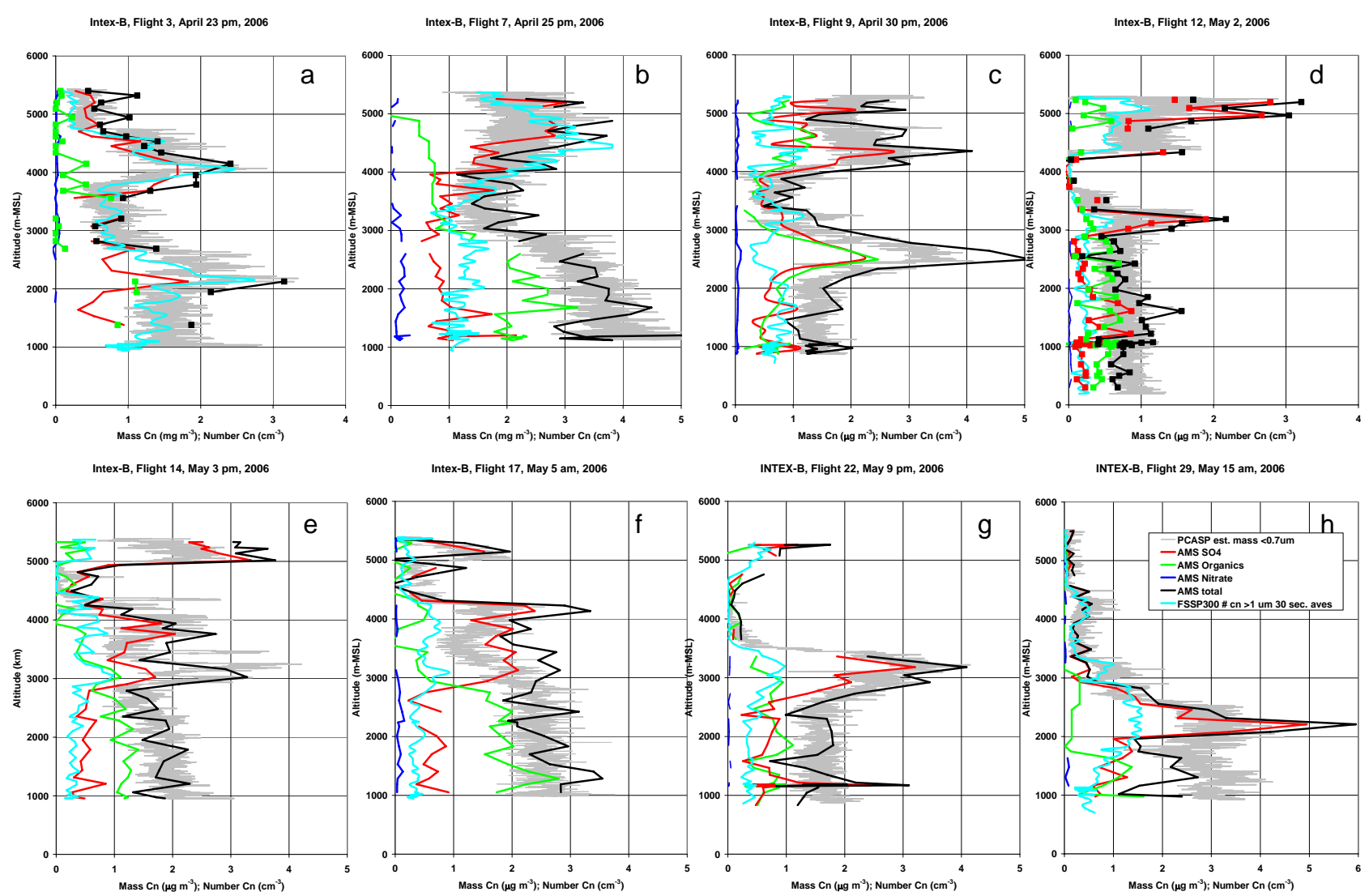

INTEX-B, Flight 29, May 15 am, 2006

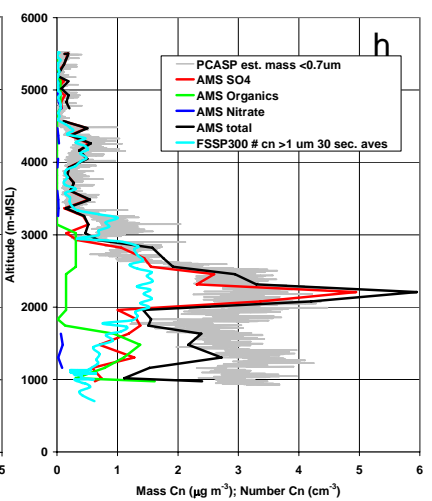

Fig. 7. Vertical profile data from several flights encountering higher altitudes plumes. Each plot includes the mass concentrations of nitrate, sulphate, and total organics measured with the AMS as well as sum of nitrate, sulphate, organics and ammonium (black line). Each AMS data point is from a one minute average. The grey curve is the mass estimated from the PCASP for particles from $0.12-0.7 \mu \mathrm{m}$ diameter assuming spherical particles and a specific gravity of $1.5 \mathrm{~g} \mathrm{~cm}^{-3}$. Also shown are 30-s averages of the number concentrations of coarse particle $(>1 \mu \mathrm{m})$ measured with the FSSP300.

coarse particles. There are no PCASP mass estimates for flight 2 as discussed in Sect. 2. The plots in Fig. 8 show temperature, $\mathrm{RH}$, ozone, the number concentrations of particles $>0.12 \mu \mathrm{m}$ (measured with the PCASP), and, in the case of flight 29, CO.

The profile from the morning of 23 April (Fig. 6) shows a $2 \mathrm{~km}$ thick layer enhanced in fine particle sulphate, coarse particles and ozone between $2 \mathrm{~km}$ and $5 \mathrm{~km}$. The afternoon profile from 23 April (Figs. 7a and 8a) shows two more distinct layers enhanced in fine and coarse particles as well as ozone, one from about $2-2.7 \mathrm{~km}$ and another about $4-4.8 \mathrm{~km}$. The fine particle mass in the lower layer consists of mostly sulphate and some organics, whereas the upper layer is almost completely sulphate. Nitrate is at or below detection limit throughout the depth of the profile. The profile from the afternoon of 25 April (Fig. 7b and 8b) shows an aerosol layer reaching to about $3 \mathrm{~km}$ composed of about $60 \%$ organic material, $30 \%$ sulphate, and a balance made up by nitrate and ammonium. Above $3 \mathrm{~km}$, the fine particle aerosol is nearly completely sulphate, and the coarse particle number concen- trations increase substantially with the sulphate. Since the number concentrations of fine particles (Fig. 8b) are much lower than below $3 \mathrm{~km}$, the similar fine particle mass concentrations indicate that the mean mass diameters of fine particles in the upper layer are larger than below $3 \mathrm{~km}$. In these three cases (Flts 2, 3 and 7), ozone increases between 15 and $30 \mathrm{ppbv}$ in association with the increases in sulphate and coarse particles.

In contrast to 22-25 April, 30 April was during a period of lower temperatures and higher RH at Whistler Peak. Back trajectories (Fig. 9) trace back to the Asian coast about 8-9 days prior to the profile. Similar to flight 3 (23 April p.m.), two distinct aerosol layers are evident in the profile from the afternoon of 30 April (Figs. 7c and 8c). The lower layer $(2-3 \mathrm{~km})$ is again a mix of organics and sulphates, but the organic mass concentration exceeds that of sulphate. The particles in the upper layer $(>4 \mathrm{~km})$, although still dominated by sulphates, contain organic material well in excess of the detection limit. Comparison of the fine particle number (Fig. 8c) and the mass concentrations (Fig. 7c) indicates that 
Intex-B, Flight 3, April 23 pm, 2006

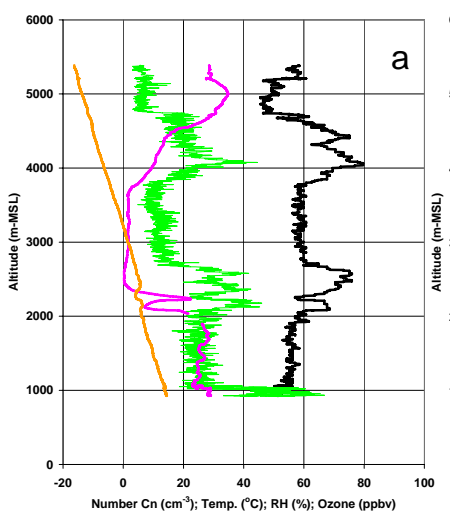

INTEX-B, Flight 14, May 3 pm [LT], 2006

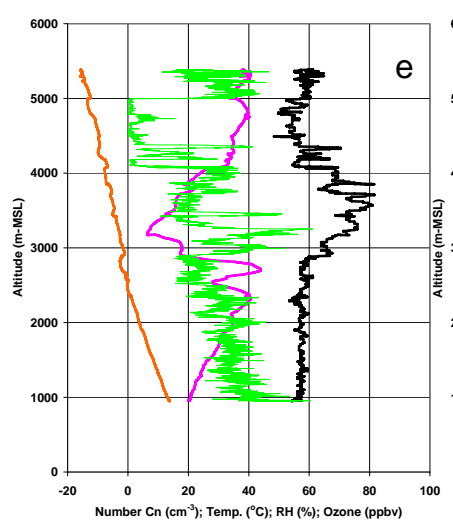

Intex-B, Flight 7, April 25 pm, 2006

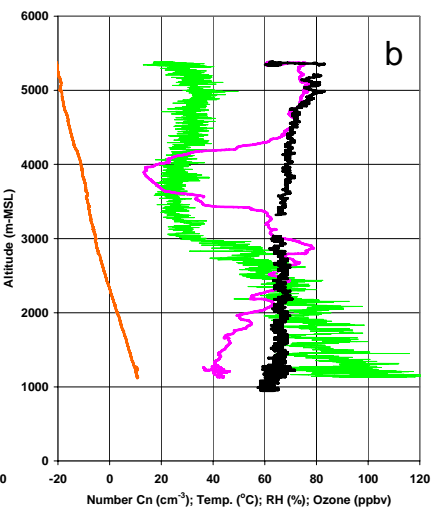

INTEX-B, Flight 17, May 5 [am], 2006

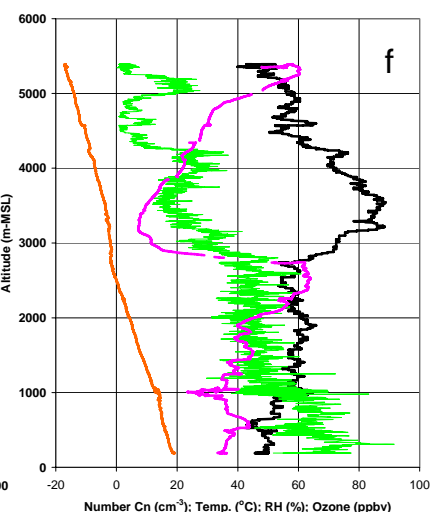

Intex-B, Flight 9, April 30 pm, 2006

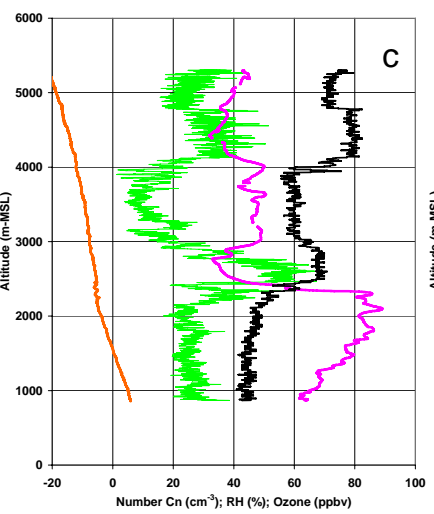

INTEX-B, Flight 22, May 9 [pm], 2006

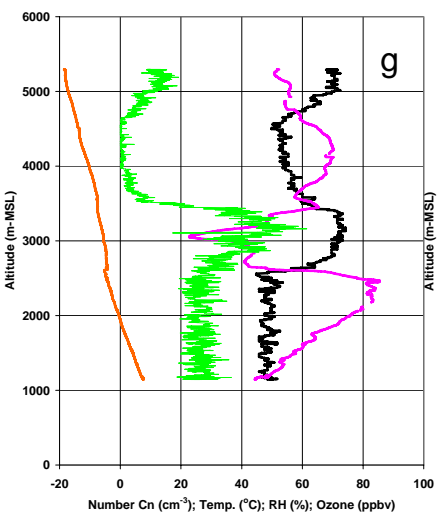

INTEX-B, Flight 12, May 2 [pm], 2006

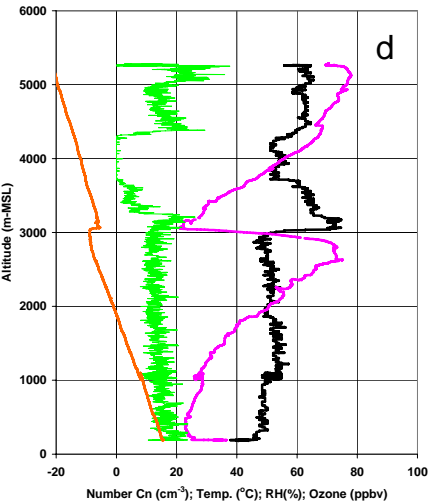

INTEX-B, Flight 29, May 15 am, 2000

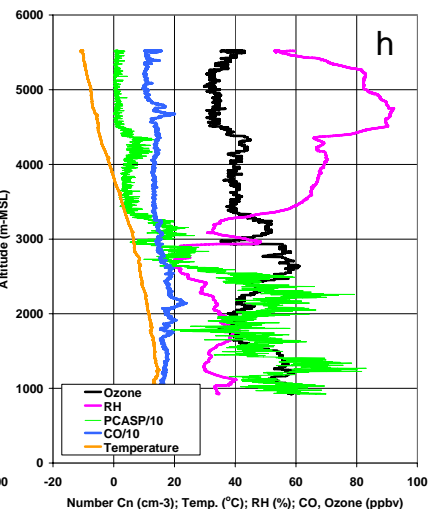

Fig. 8. Data from the same profiles as in Fig. 7, but for ozone, relative humidity (RH), temperature and the number concentrations of particles $>120 \mathrm{~nm}$ as measured with the PCASP and divided by 10. Observations of CO are shown in Fig. 8h (profile from $15 \mathrm{May}$ ).

the particles in the upper layer $(>4 \mathrm{~km})$ and in the $2-3 \mathrm{~km}$ layer are similar in mean size. Also, there are no increases in the number concentrations of coarse particles in these two layers. The size distributions from 25 April and 30 April cases are contrasted below.

2-5 May was another period of higher temperatures and lower RH at the Peak, and with it more transport of sulphate, coarse particles and ozone above $3 \mathrm{~km}$. Profile data from three flights (2 May p.m., 3 May p.m. and 5 May a.m.) are shown in Figs. $7 \mathrm{~d}$ and $8 \mathrm{~d}, 7 \mathrm{e}$ and $8 \mathrm{e}$, and $7 \mathrm{f}$ and $8 \mathrm{f}$, respectively. The lower $3 \mathrm{~km}$ of each profile is characterized by a fine particle aerosol that was relatively mixed and increasingly dominated by organic material. It is suspected that the organic aerosol up to $3 \mathrm{~km}$ was contributed from regional sources, including biogenic emissions (e.g. Sun et al., 2009). Above $3 \mathrm{~km}$, these cases each show two plumes dominated almost completely by sulphate reaching up to $3 \mu \mathrm{g} \mathrm{m}^{-3}$. On $2 \mathrm{May}$, the vertical extent and mass concentration of the upper plume is the larger than the lower plume, on 5 May the lower plume is greater than the upper plume, and the 3 May plumes are in-between. This suggests a complex mix of these plumes with some slow subsidence of the upper plume. Coarse particles were enhanced in the sulphate plumes, but the number concentrations were much smaller than observed during the 22-25 April period. Increases in ozone above $3 \mathrm{~km}$ are smaller in the upper plumes than in the lower plumes; $<10 \mathrm{ppbv}$ in the upper plumes and up to $25 \mathrm{ppbv}$ in the lower plumes.

There were two other periods of warmer air at Whistler Peak during the study: 9-11 May and 14-17 May, and plumes during these periods were found at lower levels than on the previous flights. Figure $7 \mathrm{~g}$ and $7 \mathrm{~h}$ show the particle profiles for the afternoon of 9 May and the morning of 15 May, respectively. In these cases, the peak mass concentrations occur at ca. $3.2 \mathrm{~km}$ on 9 May and $2.2 \mathrm{~km}$ on 15 May. As with most of the other cases, the plumes are principally sulphate. There is some detectable organic in the 9 May plume, but sulphate is 3-6 times higher, and the $3 \mathrm{~km}$ back trajectories for this time reach back over Asia. There was no detectable organic in the 15 May morning plume as observed by either the Cessna or at the Peak with the HR-ToF-AMS (Fig. 3c and Sun et al., 2009). The 15 May morning plume was observed at Whistler Peak for about $6 \mathrm{~h}$ and was followed by at least two days of aerosol with a high organic 


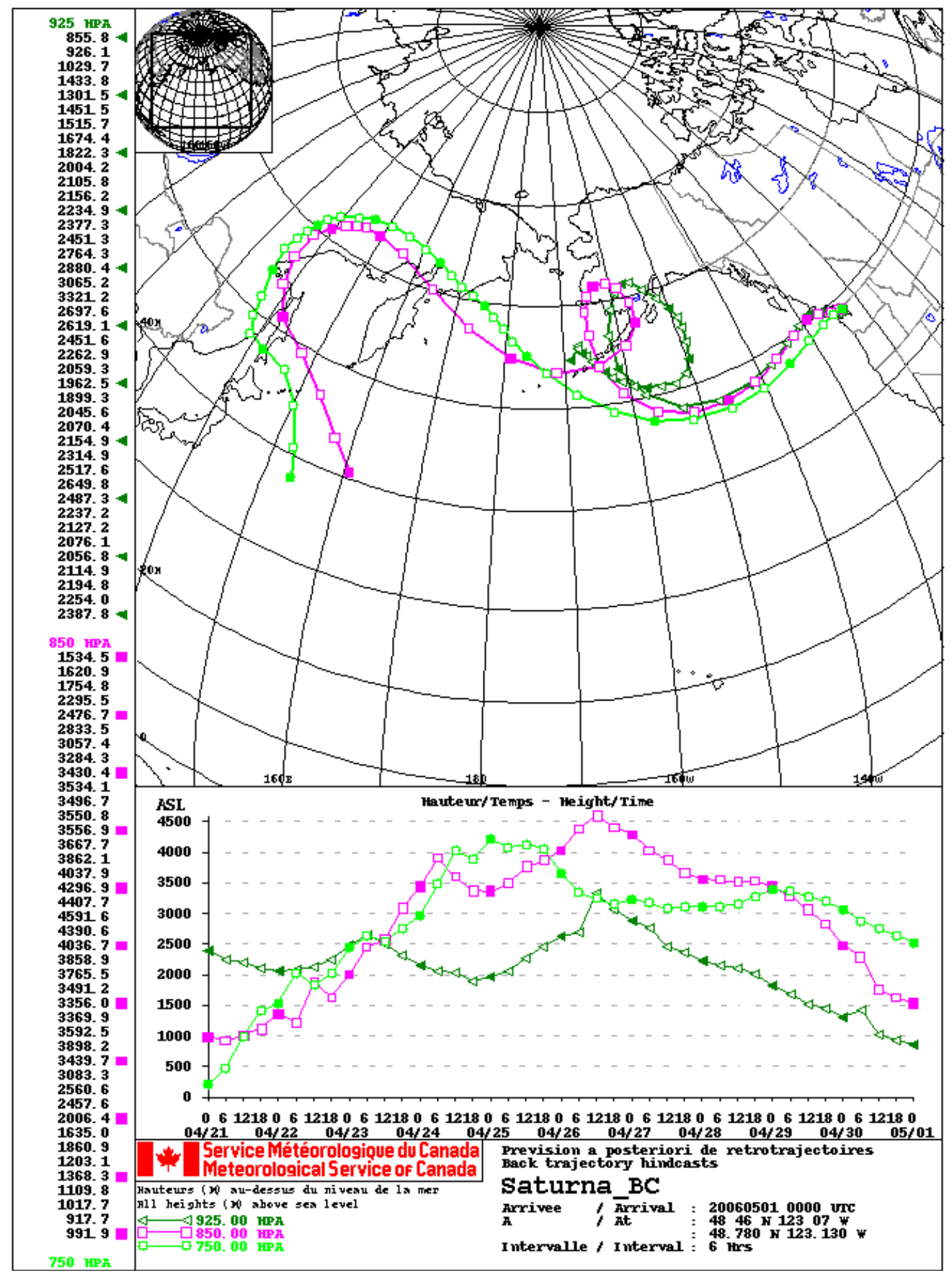

Fig. 9. Back trajectories from the Canadian Meteorological Centre for the afternoon of 30 April 2006.

fraction that is believed to have been from regional sources (Sun et al., 2009). During the morning of May 15, the air trajectory for $2-3 \mathrm{~km}$ traces back to the mid-Pacific and northern China (Fig. 9). McKendry et al. (2008) discuss the 15 May observations in the context of Asian dust storms and suggest the Taklamakan desert as the most likely source region. Coarse particles were enhanced in the sulphate layers on both 9 and 15 May, but the number concentrations were significantly higher in the 15 May case. Increases in ozone of up to $20 \mathrm{ppbv}$ were evident in the plumes on both days. 

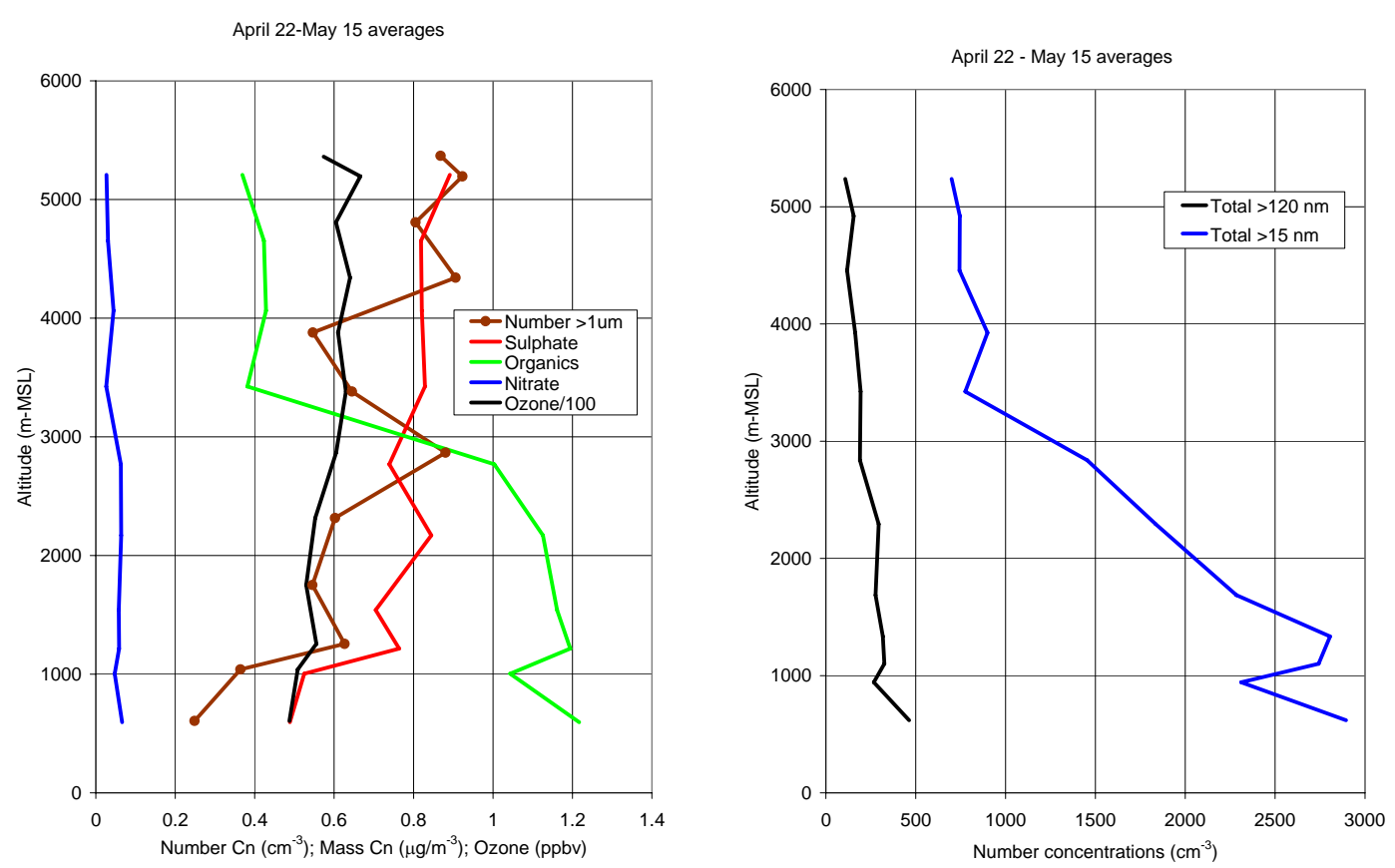

Fig. 10. Averages of the vertical profile data from 22 April to the morning of 15 May 2006 at Whistler, BC.

On May 15, the ozone increase was most pronounced from $2.5-3 \mathrm{~km}$, whereas the sulphate increase was primarily at $2-$ $2.5 \mathrm{~km}$. A substantial increase in $\mathrm{CO}$ followed more closely the increase in sulphate.

\subsection{Mean profiles}

Average profiles were calculated for observations from 22 April to the morning of 15 May, inclusive; the period of strongest trans-Pacific transport. After the morning of 15 May, the four remaining flights were dominated by local and regional organic material (McKendry et al., 2008; Sun et al., 2009). Three cases with suspected direct stratospheric influence on the ozone (flight 5 on 24 April, flight 10 on 1 May and flight 11 on 2 May) were excluded as were flights 16 and 18 (4 May and 5 May) because the profiles were limited to below $3 \mathrm{~km}$. In total, the averages in Fig. 10 are based on 13 flights all conducted during the daytime at Whistler, and close to when the MCL was at a maximum height; about $3 \mathrm{~km}$ during this period. Mean profiles of sulphate have also been discussed by van Donkelaar et al. (2008) in the context of the sulphate measurements from the NCAR C-130 and the NASA DC-8 as well as in comparison with simulations from the GEOS-CHEM model for the INTEX-B period.

The mean profiles show fine particle nitrate and organics both higher below $3 \mathrm{~km}$ and decreasing above $3 \mathrm{~km}$. It is suspected that the boundary layer organic was influenced by biogenic emissions from the valley forest. Fine particle sulphate, ozone and the coarse particle number concentrations all show gradual increases with altitude, indicative of a higher level transport source that is stronger than the surface sources. The average profiles of the number concentrations of particles $>15 \mathrm{~nm}$ and $>120 \mathrm{~nm}$ declined with altitude. As the number concentrations drop faster than the total mass concentrations, it is evident that more of the mass at higher altitudes is in larger particles, consistent with the apparent long transport times of these aerosols. Two examples of the particle size distributions follow.

\subsection{Particle size distributions}

Particle size distributions for measurements conducted on 25 April and 30 April are shown in Fig. 11. These two cases are selected because they represent a situation with a predominately sulphate plume and relatively high number concentrations of coarse particles (25 April above $3 \mathrm{~km}$; Fig. 8b), and a situation with plumes of particles of mixed organic and sulphate composition as well as fewer coarse particles (25 April below $3 \mathrm{~km}$ and April 30 above and below $3 \mathrm{~km}$; Fig. 8c). The distributions are averaged over $1 \mathrm{~km}$ altitude ranges selected to represent the above conditions.

There are considerably more particles above about $0.5 \mu \mathrm{m}$ in the 25 April number size distribution averaged for 4.3$5.3 \mathrm{~km}$ compared with the number distribution averaged for $1.8-2.8 \mathrm{~km}$ on 25 April. Below $0.5 \mu \mathrm{m}$, particle number concentrations in the 1.8-2.8 km distribution are greater than for the $4.3-5.3 \mathrm{~km}$ interval.

Number distributions at $1.8-2.8 \mathrm{~km}$ and $4.1-5.1 \mathrm{~km}$ from 30 April are relatively similar to each other, with the exception that the lower distribution indicates more particles above 
Intex-B, Flight 7, April 25, 2006

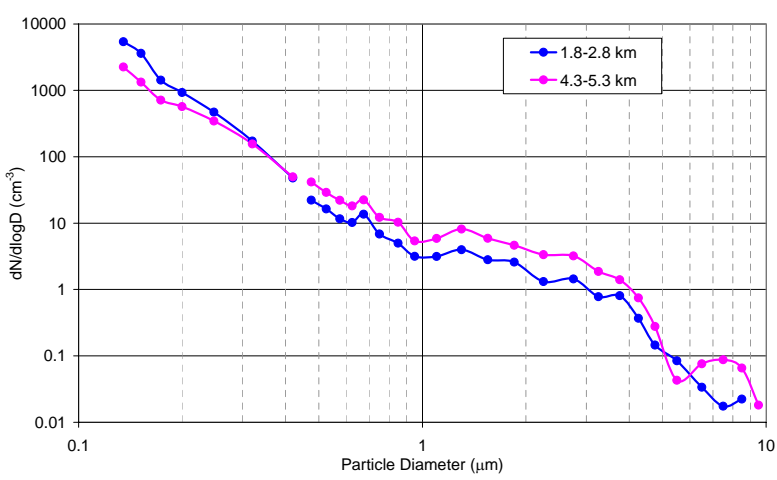

Intex-B, Flight 7, April 25, 2006

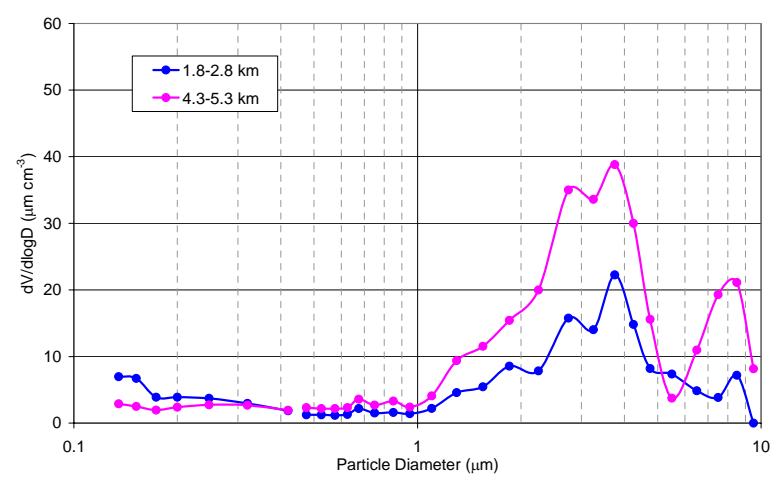

Intex-B, Flight 9, April 30, 2006

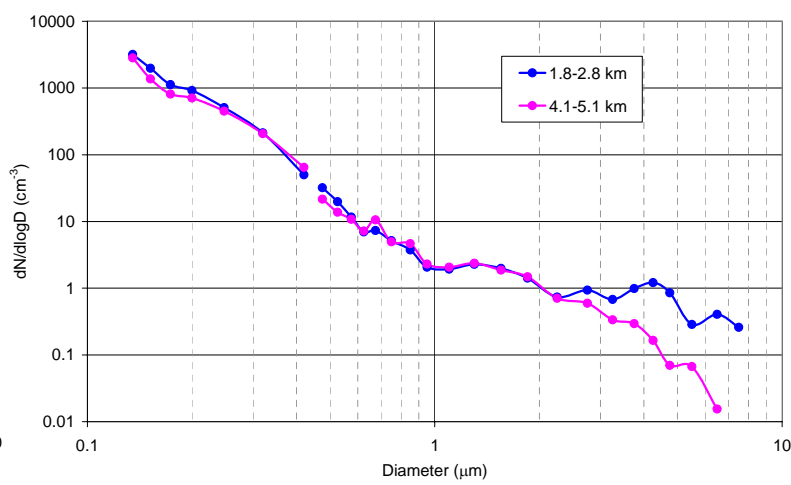

Intex-B, Flight 9, April 30, 2006

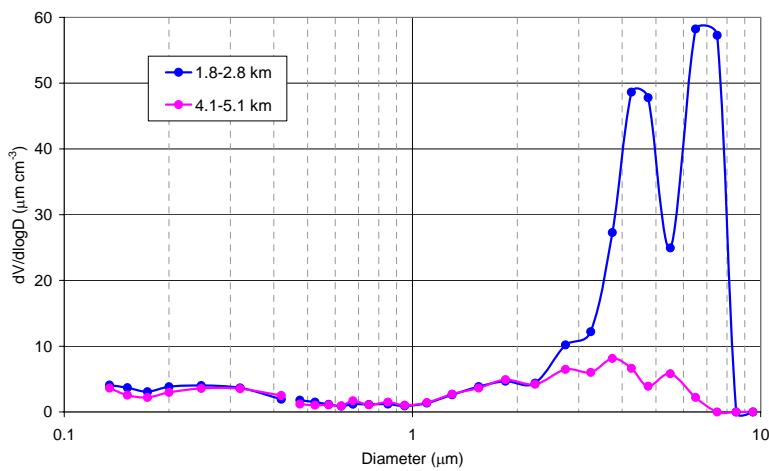

Fig. 11. Particle size distributions from flights 7 and 9 on 25 April and 30 April, respectively.

about $3 \mu \mathrm{m}$, which is likely due to local sources. In comparison to the $4.3-5.3 \mathrm{~km}$ distribution of 25 April, the 30 April distributions have substantially fewer particles in the $0.5-$ $4 \mu \mathrm{m}$ range and only slightly more particles in the measured sizes below $0.5 \mu \mathrm{m}$.

Particle volume size distributions, assuming spherical particles, are shown at the bottom of Fig. 11 for 25 and 30 April. Contrasting the distributions above $4 \mathrm{~km}$, the volume from 30 April is more evenly distributed between the fine and coarse modes whereas that from 25 April is heavily weighted by the coarse particles. The strong similarities of the lower and upper distributions on 30 April suggest that the distributions had similar origins except for the particles $>3 \mu \mathrm{m}$. The correspondence of the coarse particle distributions at both altitudes on 25 April suggests a common origin and that settling could be a connecting process. The fine particle volume distributions from 25 April are distinctly different. The lower altitude volume distribution is dominated by smaller particles, consistent with a shorter lifetime and the higher organic content; the organic mass on average was found in smaller particles relative to sulphate (Sun et al., 2009). The $4.3-5.3 \mathrm{~km}$ fine particle volume distribution is more uniform across the $0.1-1 \mu \mathrm{m}$ size range, and such a volume distribution results from a number distribution represented by a power law with a -3 slope as proposed by Junge (1963). This could result from the condensation of sulphate onto fine particles of dust that represent the lower tail of the dust particle distribution.

Chemical size distributions from the Q-AMS were noisy, due to the relatively low concentrations and short sampling times, and the altitude change without a constant pressure inlet meant particle sizes were a function of altitude. The size distribution of sulphate measured with the HR-ToFAMS at Whistler Peak during the morning of 15 May, a near completely sulphate plume, shows the sulphate peaking just above $600 \mathrm{~nm}$ vacuum aerodynamic diameter. This is at the upper size of $100 \%$ transmission into the AMS (Liu et al., 2007), and it suggests that sulphate was also present in particles above this size (600 nm VAD equates to approximately $350 \mathrm{~nm}$ geometric diameter for sulphate and assuming a spherical particle); hereafter the AMS sizing is referred to geometric diameter (GD). This is consistent with the overall larger particles observed in sulphate rich transPacific plumes. The results of the coarse particle inorganic chemistry measured at Whistler Peak follow.

\subsection{Coarse particle observations at Whistler Peak}

The fine particle chemistry from the HR-ToF-AMS at Whistler Peak is discussed by Sun et al. (2009). In this section, the relationships among sulphate, nitrate, calcium, 


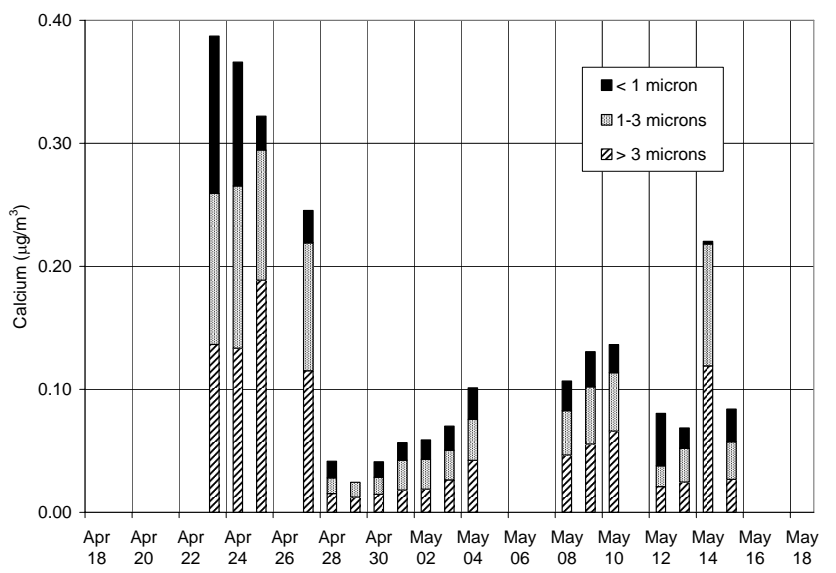

Fig. 12. Distribution of calcium in particles as a function of size at Whistler Peak, size separated using a non-rotating MOUDI impactor.

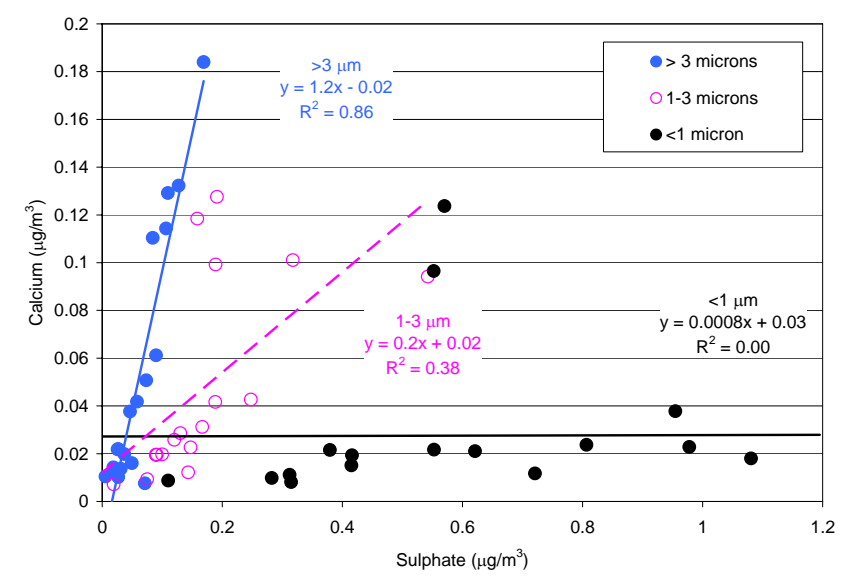

Fig. 13. Calcium versus sulphate in each of the three size intervals measured at Whistler Peak.

sodium, oxalate, acetate and formate ions in coarse particles sampled at Whistler Peak are examined; these are all water soluble compounds and therefore can underestimate the true elemental concentrations. This provides chemical information about the coarse particles that was not possible from the Cessna.

Figure 12 shows the distribution of the calcium mass concentrations in each of the three size intervals sampled at Whistler Peak during INTEX-B: $<1 \mu \mathrm{m}, 1-3 \mu \mathrm{m}$ and $>3 \mu \mathrm{m}$ diameter. The date/time indicated in Fig. 4 represents the start time of the one-day sample. With the one exception of 12 May, the calcium mass was predominantly in the coarse mode, consistent with a soil-blown dust source, and the variations in the calcium mass concentrations coincide with those in the coarse particle number concentrations at the Peak (Fig. 3c). Relative to 25 April, the calcium sampled on 30 April is very low, and this indicates that the high volume in particles $>3 \mu \mathrm{m}$ (Fig. 11) was not related to calcium.

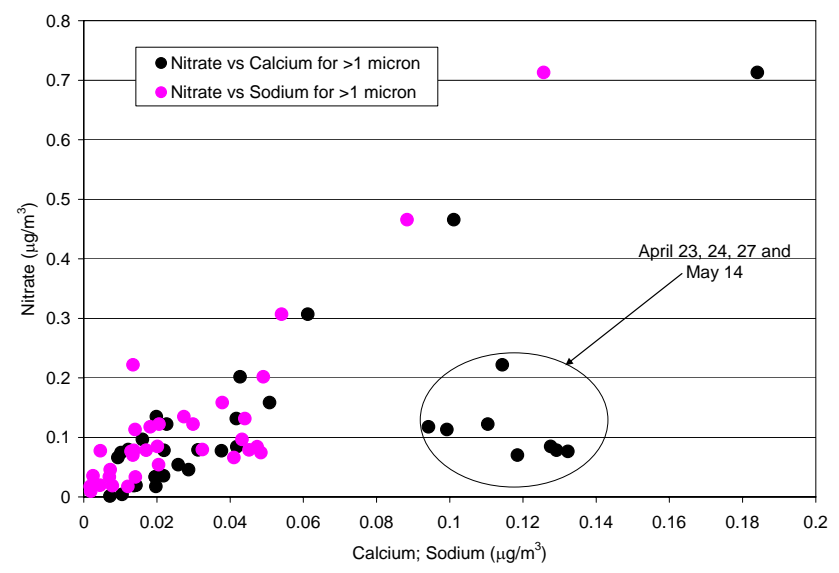

Fig. 14. Comparison of nitrate with calcium and with sodium for particles $>1 \mu \mathrm{m}$ as sampled with Moudi at Whistler Peak.

The sulphate mass concentrations are highly correlated with the calcium values in the $>3 \mu \mathrm{m}$ size range $\left(R^{2}\right.$ value of 0.86) and apparently independent of calcium in particles $<1 \mu \mathrm{m}$ (Fig. 13), suggesting that the sulphate in the particles $>3 \mu \mathrm{m}$ was strongly influenced by the presence of calcium. Most of the sulphate was present in particles $<1 \mu \mathrm{m}$ and the fine particle sulphate does not correlate with calcium. The absence of a correlation with calcium does not preclude an influence of coarse particles on the sulphate size distribution; calcium represents only a fraction of the mass of the dust particles and the influence of the dust particle on sulphate does not have to be to provide a reaction point, but rather just a condensation point.

The nitrate mass concentrations in the coarse particles (Fig. 14) are higher overall than those in the fine particle mode (Fig. 3c). Coarse particle nitrate is also well correlated with calcium (Fig. 14) with the exception of a cluster of points (circled). The correlation of coarse particle nitrate is better with sodium, and the coarse particle sodium plus calcium is sufficient to account for the ion balance with coarse particle nitrate plus sulphate. The circled points represent most of the higher calcium situations, and may indicate an excess of calcium relative to the sodium, sulphate and nitrate.

\subsection{Organic material on larger particles}

A total of 91 particles $>0.5 \mu \mathrm{m}$ collected on the C-130 during INTEX-B have been analyzed by STXM. Particles larger than $0.5 \mu \mathrm{m}$ are considered here since the particle size distributions indicate an enhancement above about this size for the dust cases. Of the 91 particles, the spectra of 37 nonspherical particles, suggesting some mineral or dust component, collected on six flights are considered here. Samples from flights 3, 4 and 7 were collected over more northerly areas, in closer proximity to Whistler, including samples from flight 7 that were collected within $100 \mathrm{~km}$ of Whistler. In contrast, samples from flights 8,9 and 11 were collected 
Table 1. Samples collected on C-130 analyzed by STXM.

\begin{tabular}{|c|c|c|c|c|c|c|c|c|c|}
\hline \multirow[t]{2}{*}{ Sample } & \multirow[t]{2}{*}{ Date } & \multirow{2}{*}{$\begin{array}{l}\text { Time } \\
\text { (LT) }\end{array}$} & \multirow{2}{*}{$\begin{array}{l}\text { Altitude } \\
\text { km- } \\
\text { MSL }\end{array}$} & \multicolumn{3}{|c|}{ \# of particles } & \multirow[t]{2}{*}{ Latitude } & \multirow[t]{2}{*}{ Longitude } & \multirow{2}{*}{$\begin{array}{l}\text { Position, } \\
\text { approx. to } \\
\text { Whistler }\end{array}$} \\
\hline & & & & $0.5-1 \mu \mathrm{m}$ & $1-3 \mu \mathrm{m}$ & $>3 \mu \mathrm{m}$ & & & \\
\hline SE03.4 & 24 April 2006 & $\begin{array}{l}14: 27- \\
14: 46\end{array}$ & 1.8 & 3 & 11 & & $\begin{array}{l}47- \\
48^{\circ} \mathrm{N}\end{array}$ & $\begin{array}{l}122- \\
123^{\circ} \mathrm{W}\end{array}$ & $\begin{array}{l}400 \mathrm{~km} \\
\text { south }\end{array}$ \\
\hline SE04.2 & 26 April 2006 & $\begin{array}{l}13: 21- \\
13: 40\end{array}$ & 5.3 & 2 & & 1 & $\begin{array}{l}48- \\
48.3^{\circ} \mathrm{N}\end{array}$ & $\begin{array}{l}134.6- \\
135^{\circ} \mathrm{W}\end{array}$ & $\begin{array}{l}700 \mathrm{~km} \text { WSW } \\
\text { over ocean }\end{array}$ \\
\hline SE07. & 3 May 2006 & $\begin{array}{l}17: 32- \\
17: 47\end{array}$ & 5.65 & & 2 & & $\begin{array}{l}48.9- \\
49.9^{\circ} \mathrm{N}\end{array}$ & $\begin{array}{l}123.4- \\
123.0^{\circ} \mathrm{W}\end{array}$ & $\begin{array}{l}100 \mathrm{~km} \text { south } \\
\text { to overhead Whistler }\end{array}$ \\
\hline SE08.3 & 5 May 2006 & $\begin{array}{l}18: 37- \\
18: 50\end{array}$ & 1.8 & & 3 & 7 & $\begin{array}{l}44.0- \\
43.2^{\circ} \mathrm{N}\end{array}$ & $122.8^{\circ} \mathrm{W}$ & $\begin{array}{l}1000 \mathrm{~km} \text { south } \\
\text { (over Oregon) }\end{array}$ \\
\hline SE09. & 8 May 2006 & $\begin{array}{l}23: 09- \\
23: 24\end{array}$ & 2.8 & 4 & 1 & & $\begin{array}{l}44.1- \\
44.9^{\circ} \mathrm{N}\end{array}$ & $\begin{array}{l}121.7- \\
122.3^{\circ} \mathrm{W}\end{array}$ & $800 \mathrm{~km}$ south \\
\hline SE11. & 11 May 2006 & $\begin{array}{l}19: 35- \\
19: 46\end{array}$ & 0.8 & & 3 & & $\begin{array}{l}40.3- \\
40.9^{\circ} \mathrm{N}\end{array}$ & $\begin{array}{l}125.2- \\
125.7^{\circ} \mathrm{W}\end{array}$ & $\begin{array}{l}1000 \mathrm{~km} \text { SSW } \\
\text { over ocean }\end{array}$ \\
\hline
\end{tabular}

more to the south over parts of Oregon and off its coast. Samples from flights 3 and 4 were also during the period of highest dust observed at Whistler (22-27 April). The samples were collected on three C-130 flights for INTEX-B: 24 April, 26 April and 5 May. Table 1 summarizes the sampling details of the 37 particles by flight number, date, time, number of particles in size range, altitude, latitude and longitude and approximate location.

Optical density spectra over an energy range of 280$320 \mathrm{eV}$ for each of the 37 particles are shown in Fig. 15. The fundamental functional group identification has been described by Russell et al. (2002). Takahama et al. (2007) introduced and applied a classification of many STXM spectra collected from a number of studies into 14 categories, including a few of the samples discussed here, into functional groups. This classification is based on the relative strengths of the various identified functional groups as well as other non-organic components such as potassium and carbonate (Russell et al., 2002).

The optical density spectra of the 37 particles fall into 10 of the categories from Takahama et al. (2007). One half of the particles from flight 3 fall into category "f" that exhibits significant absorbance in the carboxylic region as well as high absorbance in the $\mathrm{K}$ and carbonate regions; this group has strong similarities to soil samples (Takahama et al., 2007). This suggests particles with dust and possibly biomass burning origins. It is consistent with secondary organic aerosol (SOA) condensed on a carbonate particle, but it can not be distinguished from OA deposition or other possible transfers of organic substances at the dust source. The other half of the flight 3 particles are spread among the six categories: "a", "b", "d", "e", "i " and "j". Following Takahama et al. (2007), type "a" particles are dominated by the carboxylic peak, while groups 'b', 'd' and 'e' exhibit varying degrees of absorbance in the alkyl, alkene and carboxyl regions. Category ' $\mathrm{e}$ ' is close to category " $c$ " in Takahama et al. (2007) with the exception of showing absorbance in the alkyl region rather than the ketone region; category 'c' was identified as surface-oxidized primary carbon, possibly including black carbon (Maria et al., 2004) that were found exclusively in samples from ACE-Asia. Type "i" and " $j$ " spectra exhibit characteristics of biomass burning (potassium and the multifunctional hulis-like spectrum with a main carboxyl peak). This may be interpreted as biomass burning-derived secondary organic aerosol either deposited or formed on dust or soil particles.

The smaller particles from flight 4 fall into category "d", and the two coarse particles from this flight fall in category "n" that shows the strongest absorbance in the alkyl and carboxylic regions. Most of the type " $n$ " samples discussed by Takahama et al. (2007) were collected in Mexico City. Both samples from flight 7 fall into category ' $b$ ' and include evidence for diesel emissions and soot (Takahama et al., 2007).

All of the particles in categories "a", "b", "f" and "h" are $1 \mu \mathrm{m}$ or larger. Each of the particles between $0.5 \mu \mathrm{m}$ and $1 \mu \mathrm{m}$ from flights 3 and 4 fall into a separate category ("d", "e", "i", "j" and "n") suggesting more variability in these smaller particles.

Particles from flight 8 dominate those collected at the more southerly locations; they are also the only samples of coarse 


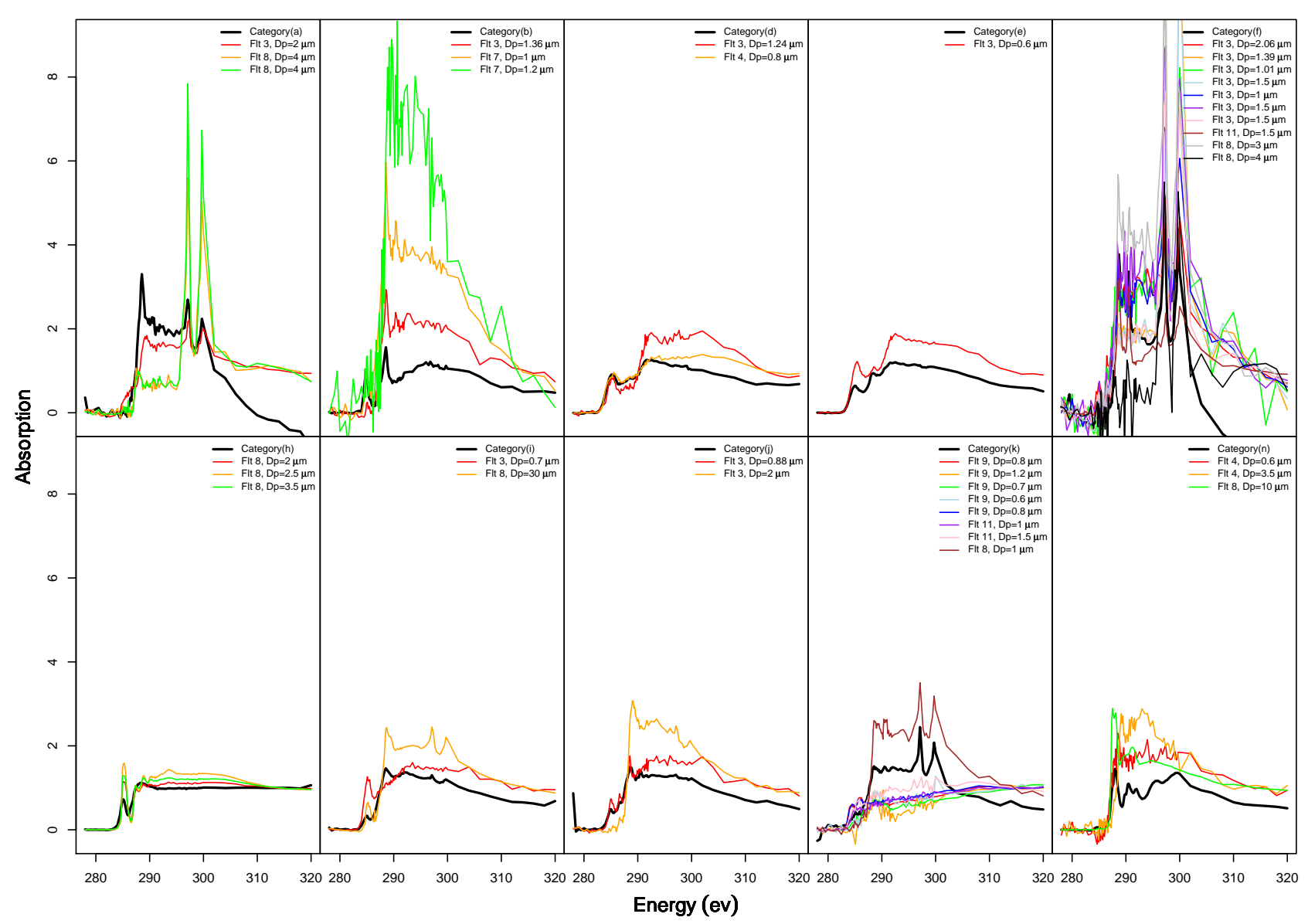

Fig. 15. Energy spectra for samples from C-130 analyzed by STXM. The samples are classified according to Takahama et al. (2007).

particles from flights 8,9 and 11 . Seven of the 10 samples from flight 8 particles fall in categories "a" (strong carboxyl absorbance), "f" (discussed above) and "h". Category "h" was associated with an urban region and characterized by heterogeneous surfaces. All but one of the smaller particles from flights 9 and 11 fall into group " $k$ ", and group " $k$ " also includes one particle from flight 8 . In general all of the particles in category " $k$ " are relatively small; the median size is $0.9 \mu \mathrm{m}$. According to Takahama et al. (2007), type " $\mathrm{k}$ " particles lack a carboxylic peak and any other distinct functional group features, but based on the normalized carbon content of these particles, this may not be due to the lack of carbonaceous material (Maria et al., 2004). One explanation advanced by Takahama et al. (2007) is that this type of particle is the result of relatively long exposures (days) of diesel $\mathrm{PM}$ to water vapour and sunlight.

Finally, significant concentrations of formate were measured by IC in the size segregated samples collected at Whistler Peak and found to be associated with coarse particles during the late April period as well as 4-5 May (Fig. 16). Acetate concentrations were an order of magnitude smaller than formate, except for 28 April when acetate in the coarse particles was about twice that of formate. There was no detectable oxalate in any of the coarse particle samples at Whistler Peak, but oxalate was found in some of the fine particle samples.

\section{Discussion}

Several cases of fine particle plumes resulting from transPacific transport were observed between $2 \mathrm{~km}$ and $5.3 \mathrm{~km}$ at Whistler, BC from 22 April 2006 to 15 May 2006. The chemical composition of most of the plumes was dominated by sulphate that ranged from $1-5 \mu \mathrm{g} \mathrm{m}^{-3}$ for particles measured with the AMS; the AMS samples particles $0.1-0.5 \mu \mathrm{m}$ GD with approximately $100 \%$ efficiency. Particulate nitrate, measured with the AMS, was at least an order of magnitude smaller than sulphate. The observations at Whistler Peak indicate sulphate mass was also present in the coarse particles at concentration levels on average about one half of those measured in the fine particles. Determining the distribution of sulphate with respect to size is important for assessing changes in Asian emissions that reach North America; e.g. van Donkelaar et al. (2008) interpreted these INTEX-B 
measurements with the GEOS-Chem model and calculated that $60 \%$ of the $<2.5 \mu \mathrm{m}$ sulphate at $600 \mathrm{hPa}$ (about $4 \mathrm{~km}$ ) was of Asian origin, and estimated a $72-85 \%$ increase in the relative contribution of East Asian sulfate to the total springtime burden off the northwest coast of the United States since 1985.

The presence of a predominantly sulphate aerosol is consistent with past observations (e.g. Brock et al., 2004) as well as others during INTEX-B (Peltier et al., 2008; Dunlea et al., 2008). However, in contrast with Brock et al. (2004) the present observations exhibit a strong coincidence of fine particle sulphate with coarse dust particles. The coarse particle number concentrations increased in all sulphate plumes between $2 \mathrm{~km}$ and $5 \mathrm{~km}$. Most of the coarse particle volume in the $4-5.3 \mathrm{~km}$ layer on 25 April was between $1 \mu \mathrm{m}$ and $5 \mu \mathrm{m}$ based on an optical size measurement, an observation consistent with the coarse particle distributions observed at Whistler Peak throughout the study (McKendry et al., 2008). Much closer to the dust origin, measurements of the size distribution of Asian dust in Korea during April 2006 found a volume mode between $1 \mu \mathrm{m}$ and $6 \mu \mathrm{m}$ aerodynamic diameter (Lee et al., 2007), similar to the present observations. The fine particle size distributions in the sulphate plumes were also larger when dust particles were present and the organic mass concentrations were lower. The ion chemistry of the coarse particles at Whistler Peak indicates both calcium and sodium in comparable quantities, and each with reasonable associations with nitrate and with sulphate. By comparison, the ion compositions of coarse particles sampled at various altitudes and relatively close to the Asian coast also show calcium distributed relatively uniformly from the surface to $7 \mathrm{~km}$, and sodium levels comparable to calcium only below $0.5 \mathrm{~km}$ over the ocean (Kline et al., 2004). The measurements of Kline et al. (2004) also show that between $20 \%$ and $30 \%$ of the sulphate off the Asian coastline was in coarse particles, and the higher fractions were found in particles sampled above $2.5 \mathrm{~km}$. Between $70 \%$ and $90 \%$ of the nitrate sampled by Kline et al. (2004) was in the coarse size range. The Gobi and Taklamakan deserts are likely origins of the high dust episodes observed at Whistler (e.g. McKendry et al., 2008), and the mix of calcium and sodium is consistent with such origins; salt lakes as well as clay and sandy soils are widely distributed across these regions leading to enriched sodium in the coarse particles (Zhang et al., 2004; Yuan et al., 2006). However, considering the observations of Kline et al. (2004), the ocean as a source of the sodium at concentrations comparable to those of calcium can not be excluded. The coarse particle sulphate results from any of three processes: the condensation of acidic sulphate from the gas phase, heterogeneous reactions of $\mathrm{SO}_{2}$ on the dust particles during transport to form $\mathrm{CaSO}_{4}$ (e.g. Song and Carmichael, 1999), and directly from the dust emissions as the Mongolian region can also be a primary source of $\mathrm{CaSO}_{4}$ (Zhang et al., 2004; Yuan et al., 2006). Nitrate measured in the coarse particles at Whistler Peak reached $0.7 \mu \mathrm{g} \mathrm{m}^{-3}$, and the

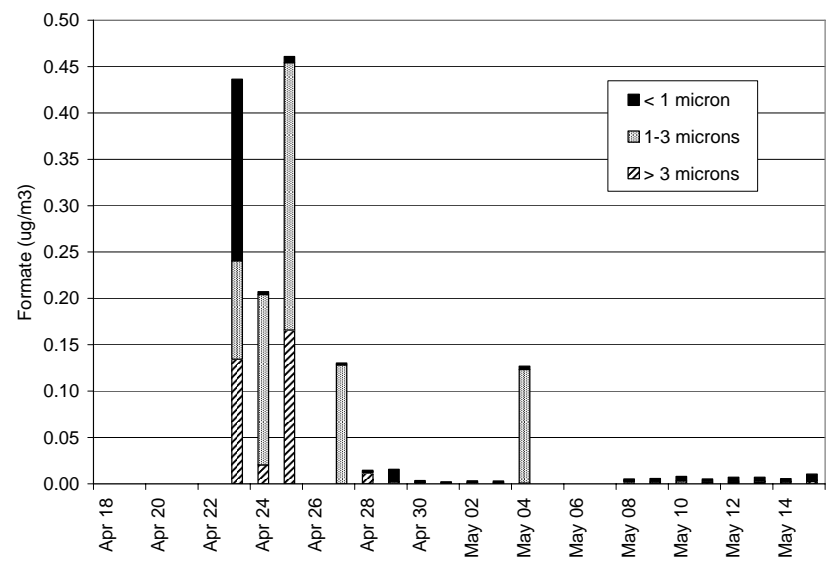

Fig. 16. Distribution of formate in particles as a function of size at Whistler Peak, size separated using a non-rotating MOUDI impactor.

mean value over the period was about $0.1 \mu \mathrm{g} \mathrm{m}^{-3}$. $\mathrm{NaNO}_{3}$ or $\mathrm{Ca}\left(\mathrm{NO}_{3}\right)_{2}$ are well known to result from the reaction of $\mathrm{HNO}_{3}$ with $\mathrm{NaCl}$ or $\mathrm{CaCO}_{3}$. It is evident that the coarse particles played a significant role in defining the physics and inorganic chemistry of the trans-Pacific aerosol observed at Whistler during INTEX-B. Potential effects of the dust particles on the organic mass in these plumes are considered next.

\subsection{Organic matter on dust particles}

The relationship of the fine particle organic mass concentrations with the number concentrations of coarse particles in the predominantly sulphate plumes is examined using the data making up the eight profiles shown in Fig. 7. In Table 2 the mean values of the organic mass concentrations, the sulphate mass concentrations, the ratio of organic to sulphate masses and the number concentrations of particles $>1 \mu \mathrm{m}$ (measured with the FSSP 300) are summarized by three groups. Group 1 represents transported plumes, identified by sulphate $>1 \mu \mathrm{g} \mathrm{m}^{-3}$ at altitudes of $3 \mathrm{~km}$ and above, except for flights 22 and 29 when plume levels were lower and altitudes of $2.5 \mathrm{~km}$ and $2.0 \mathrm{~km}$ respectively are used; the separation point of $1 \mu \mathrm{g} \mathrm{m}^{-3}$ is arbitrary, but it isolates the most significant plumes and is the same plume identification used by Dunlea et al. (2008). The average fine particle mass concentrations of sulphate and organics estimated for Asian sources from the C-130 were $2.0 \mu \mathrm{g} \mathrm{m}^{-3}$ and $0.85 \mu \mathrm{g} \mathrm{m}^{-3}$, respectively (Dunlea et al., 2008). Their value of sulphate is close to the present mean $\left(1.9 \mu \mathrm{g} \mathrm{m}^{-3}\right)$, and their average organic concentration is about twice the present value $\left(0.43 \mu \mathrm{g} \mathrm{m}^{-3}\right)$. The reason for their higher organic value is likely the higher contribution from one plume dubbed the "Young Asian Layer" that the C-130 sampled just above $6 \mathrm{~km}$ on 1 May 2006. Group 2 in Table 2 represents all cases above $3 \mathrm{~km}$, again using $2.5 \mathrm{~km}$ and $2.0 \mathrm{~km}$ for flights 22 and 29, with sulphate $<1 \mu \mathrm{g} \mathrm{m}^{-3}$. This is essentially the 
Table 2. Summary of aerosol profile data separated by sulphate concentration and altitude range.

\begin{tabular}{llllll}
\hline Flight \# & $\begin{array}{l}\text { Alt. } \\
(\mathrm{m}-\mathrm{msl})\end{array}$ & $\begin{array}{l}\text { Organic } \\
\text { Mass Cn } \\
\left(\mu \mathrm{g} \mathrm{m}^{-3}\right)\end{array}$ & $\begin{array}{l}\text { Sulphate } \\
\text { Mass Cn } \\
\left(\mu \mathrm{g} \mathrm{m}^{-3}\right)\end{array}$ & $\begin{array}{l}\text { Organic to } \\
\text { Sulphate } \\
\text { ratio }\end{array}$ & $\begin{array}{l}\text { FSSP300 } \\
\#>1 \mu \mathrm{m} \\
\left(\mathrm{cm}^{-3}\right)\end{array}$ \\
\hline \multicolumn{6}{l}{ Group 1 } \\
except $>2.5 \mathrm{~km}$ and
\end{tabular}

Group 2 - sulphate mass concentration $<1 \mu \mathrm{g} \mathrm{m}^{-3}$ and $>3 \mathrm{~km}$, except $>2.5 \mathrm{~km}$ and $>2.0 \mathrm{~km}$ for flights 22 and 29 , respectively.

\begin{tabular}{llllll}
3 & 4367 & 0.10 & 0.49 & 0.20 & 0.53 \\
7 & 3538 & 0.78 & 0.76 & 1.03 & 1.39 \\
9 & 3862 & 0.48 & 0.66 & 0.73 & 0.62 \\
12 & 3868 & 0.06 & 0.31 & 0.19 & 0.15 \\
14 & 4401 & 0.59 & 0.14 & 4.29 & 0.25 \\
17 & 4948 & 0.08 & 0.51 & 0.16 & 0.18 \\
22 & 4422 & 0.13 & 0.26 & 0.52 & 0.18 \\
29 & 4459 & 0.03 & 0.22 & 0.13 & 0.21 \\
Mean & 4233 & 0.28 & 0.42 & 0.91 & 0.44 \\
Median & 4384 & 0.12 & 0.40 & 0.36 & 0.23 \\
\hline
\end{tabular}

Group 3 - all sulphate mass concentrations $<3 \mathrm{~km}$, except $<2.5 \mathrm{~km}$ and $<2.0 \mathrm{~km}$ for flights 22 and 29 , respectively.

$\begin{array}{llllll}3 & 1823 & 0.60 & 0.63 & 0.96 & 1.31 \\ 7 & 1929 & 2.14 & 0.89 & 2.40 & 1.29 \\ 9 & 1588 & 0.87 & 0.85 & 1.02 & 0.64 \\ 12 & 1698 & 0.44 & 0.30 & 1.47 & 0.22 \\ 14 & 1865 & 1.08 & 0.54 & 2.01 & 0.33 \\ 17 & 1631 & 2.04 & 0.67 & 3.06 & 0.35 \\ 22 & 1491 & 0.70 & 0.73 & 0.96 & 0.39 \\ 29 & 1456 & 0.71 & 0.98 & 0.73 & 0.82 \\ \text { Mean } & 1685 & 1.07 & 0.70 & 1.57 & 0.67 \\ \text { Median } & 1665 & 0.79 & 0.70 & 1.25 & 0.51\end{array}$

free troposphere aerosol without direct influence of Asian sources. The mean and median values of sulphate for Group 2 are at the upper end of the range of monthly geometric mean sulphate concentrations measured at Whistler for April and May from 2002-2006 (0.06-0.40 $\mu \mathrm{g} \mathrm{m}^{-3}$; Macdonald et al., 2006) and agree well with the "free troposphere" estimate of $0.38 \mu \mathrm{g} \mathrm{m}^{-3}$ for sulphate given by Dunlea et al. (2008). Dunlea et al. (2008) estimate an average "free troposphere" fine particle organic mass concentration of $0.18 \mu \mathrm{g} \mathrm{m}^{-3}$ that falls in between the median and mean values of Group 2 . Group 3 is everything below $3 \mathrm{~km}$, or $2.5 \mathrm{~km}$ and $2.0 \mathrm{~km}$ in the cases of flights 22 and 29, and this group represents the aerosol more strongly influenced by regional sources. In each case, the organic mass concentrations are averaged over more than five minutes, which lowers the detection limit for the organic to $\leq 0.27 \mu \mathrm{g} \mathrm{m}^{-3}$ (Sun et al., 2009). In Fig. 17, the mass concentrations of organics and of sulphate for the in-

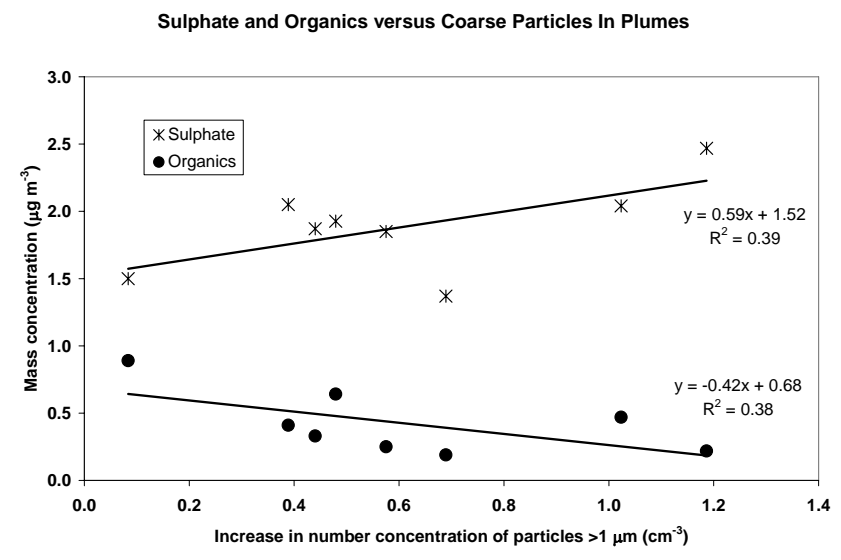

Fig. 17. The mass concentrations of total organics and sulphate versus the increase in the coarse particle number concentration in the sulphate plumes. Points are from the group one case in Table 2. The increase in coarse particles is the difference between the group one concentration and the corresponding group two concentration.

plume points (Group 1) are plotted versus the increase in the coarse particle number concentration; the increase is defined as the Group 1 value minus the corresponding flight value from Group 2, i.e. the increase of those particles inside the plumes relative to outside of the plumes in the same altitude range. Linear fits applied to the data indicate an increase in sulphate mass and a decrease in organic mass with increasing coarse particle number concentrations; these models are significant at confidence levels $>90 \%$ for each of the sulphate and organic curves. The high intercept of the fit to the sulphate curve suggests that much of the sulphate was produced independent of the coarse particles, and this would be consistent with most of the sulphate being produced by oxidation during transport (e.g. Brock et al., 2004). The fact that sulphate increases coincident with the coarse particles might represent the dust having travelled over $\mathrm{SO}_{2}$ sources. The intercept of the organic curve is higher than the median and mean values of the organic mass concentration of Group 2 and suggests the presence of some organic mass in the plumes decreasing with fewer coarse particles. The slope of the organic curve indicates a reduction of fine particle organic with higher concentrations of coarse particles. Among other things, variability in this relationship could follow from differences in trajectories, in the origins of the coarse particles and in the source regions the aerosol passed over. More data points are needed to confirm these relationships at higher levels of significance. Next, the presence of organic compounds on the coarse particles is considered.

The characteristics of the organic functional groups, derived from the STXM analyses, show a variety of organic mixtures in coarse particles sampled during INTEX-B. The particles collected from the $\mathrm{C}-130$ closer to Whistler were somewhat different from those collected farther south; 14 of the 19 northern particles were in classified in groups "b", "d", "f" and " $\mathrm{j}$ ", and 11 of the 18 southern particles were classi- 
fied in groups "h" and "k". Category "f", into which seven of the particles from the flight to Whistler (Flight 3) were classified, is identified with particles that possess strong STXM signatures for carbonate, potassium and the carboxyl functional group. All particles in "f" are $1 \mu \mathrm{m}$ or larger. Group " $k$ " particles lack specific identifying features, but still contain organics and overall they are smaller than the group "f" particles. The group " $f$ " particles containing carbonate and carboxylates parallel the observations of increased calcium and formate in the coarse particles sampled at Whistler during 22-26 April (Fig. 12); potassium was present in the Whistler Peak samples but at much lower concentrations than calcium and formate. Wang et al. (2007) describe measurements of formate, acetate and oxalate in PM2.5 and PM10 samples collected at sites in and around Beijing, China from the spring of 2002 to the winter of early 2004. Formate in fine particles was found to be the lowest in the spring samples leading Wang et al. (2007) to suggest that dust from spring storms over western and northern China may have removed much of the fine particle formate. Wang et al. (2007) made no observations of PM10 during the spring sampling period, but their suggestion that formate was removed by dust particles is consistent with the present observations.

The present observations suggest there was a reduction in fine particle organic mass with increasing levels of coarse particles and indicate that organics were present in coarse particles that include signatures for dust. Possible explanations for these observations are considered. A reduction or loss of fine particle organic mass appears to be a common observation for plumes after leaving Asia. Cloud scavenging of fine aerosol particles leaving the Asian coastline was advanced by Lim et al. (2003) to explain their observations from a ship during ACE-Asia that showed a relatively rapid reduction in $\mathrm{OC}$ compared to $\mathrm{EC}$ with increasing transport time away from the Asian coastline. They attributed that result to the preferential cloud scavenging of OC relative to EC. During INTEX-B, Peltier et al. (2008) observed a reduction of water soluble organic carbon (WSOC) in transPacific plumes and suggested that WSOC leaving Asia was scavenged by clouds. Dunlea et al. (2008) also assumed the cloud scavenging hypothesis to explain relatively low levels of organics in the fine particle aerosol plumes from Asia. Ambient organic aerosol particles, including WSOC, are less efficiently scavenged by nucleation than sulphate particles unless the organic and sulphate are mixed (e.g. Lohmann et al., 2004). Since in or near urban source regions, organics tend to be found in smaller particles than sulphate (e.g. Zhang et al., 2005; Broekhuzien et al., 2006), the overall efficiency by which they are subject to nucleation scavenging in clouds will be lower than that of sulphate. Nevertheless, for particularly cloudy conditions with significant precipitation, such as in the case of Lim et al. (2003), cloud scavenging is likely to sharply reduce fine particle organics as well as sulphates. In the present case, the observation of dust particles coincident with the sulphate makes it more difficult to adopt the cloud scavenging hypothesis as the sole explanation for the reduction in the fine particle organic mass. If the dust and sulphur sources are transported independently off the Asian continent and then mixed during transport across the Pacific Ocean, they should not correspond as closely as observed here. On the other hand, if the dust is first transported over industrial regions, as during 15-20 April 2006 when dust was a serious problem for the Beijing region (e.g. Papayannis et al., 2007), and the mix of fine and coarse particles enters a cloud, then for the cloud scavenging hypothesis to be the sole viable explanation of the loss of fine particle organics the coarse particles must be scavenged much less efficiently than the fine particles, i.e. they must not increase significantly in size due to water condensation. Otherwise, they are removed with a similar efficiency as the fine particles and their presence in the sulphate plumes contradicts the cloud scavenging hypothesis. Of some of the likely compositions of the coarse particles sampled at Whistler, calcium nitrate, sodium formate and sodium nitrate are highly soluble (comparable to ammonium sulphate), while calcium sulphate, sodium sulphate and calcium formate are much less soluble. Calculations done using the aerosol-cloud adiabatic parcel model described by Shantz et al. (2008) indicate that even if only $1 \%$ of a particle in the $1-5 \mu \mathrm{m}$ size range is highly water soluble (a reasonable level based on the current observations) that these particles will quickly grow to sizes of between $10 \mu \mathrm{m}$ and $28 \mu \mathrm{m}$ in moderate cumulus; the size varies depending on the concentrations of fine particles. The wet sizes of these coarse particles are also larger than those of the activated fine aerosol. Thus, the scavenging efficiency of these coarse particles is very likely to be at least as high as that of the fine aerosol. Also, relatively large quantities of dust may significantly modify cloud properties including their precipitation efficiency. Lofting of fine and coarse particles by dry convection (Dickerson et al., 2007) could also explain the present of dust in these plumes, but not the absence of fine particle organic.

Evidence from sampling over the Yellow Sea during ACEAsia shows that dust layers were often elevated in fine particle organics before crossing the Pacific (Maria et al., 2003). The dust source, primarily the Taklamakan desert, was found to be spatially distinct from sources of $\mathrm{CO}$, sulphate and nitrate. The transport of large dust plumes over anthropogenic regions (e.g. Beijing) during INTEX-B may contrast with the observations of Maria et al. (2003) and others (e.g. Kline et al., 2004), suggesting that transport patterns and mixing of sources over eastern Asia may have been different during INTEX-B than ACE-Asia. Differences of the INTEX$B$ period with other years are also evident in the Whistler Peak data record from 2002 to 2006 that shows the April and May monthly averaged particle calcium concentrations higher during 2006 than any of the previous years (Macdonald et al., 2006). 
The basic sources of fine particle organic are primary emissions from combustion and SOA formation from the oxidation of natural and anthropogenic precursors. The dust clouds that affected Beijing during April 2006 were intense, but reaching optical depths of 4 or more (Papayannis et al., 2007) means that the dust surface areas were towards the lower end of that in a typical atmospheric liquid water cloud. Even in liquid water clouds, the scavenging by various coagulation mechanisms of fine particles by cloud droplets is relatively inefficient except for the removal of particles smaller than about $30 \mathrm{~nm}$ (e.g. Jacobson, 1999), and therefore coagulation scavenging with dust particles will not account for the absence of fine particle organics from primary emission. The presence of relatively high concentrations of settling dust particles can affect the dynamics and the temperature structure of the local environment; the dust can increase the stabilization of the near surface atmosphere via its downward momentum due to settling and its reflection of solar radiation. Such effects could contribute to some separation of the organic material emitted near the surface from the dust that is above the surface layer. Secondary formation of organic material via the condensation of low volatility products of VOC oxidation onto dust particles or by heterogeneous reactions of VOCs on the surfaces of dust particles (e.g. Sullivan and Prather, 2007) are possible mechanisms for the removal of precursors of fine particle organic aerosol. However, it can not be concluded that these processes are responsible for the present observations of organics on dust, as organics likely exist on dust at the source of the dust (e.g. Mayol-Bracero, 2008). If the SOA formation occurs mostly within two days of the emissions of the precursor (as some observations might suggest, e.g. Dunlea et al., 2008), then for situations with the particle surface and mass dominated by coarse particles, i.e. extremely high dust loadings, it is likely that SOA formation on the coarse particles would be favoured and this would also reduce the potential for further SOA formation. Regardless of the time scale, it is clear that any SOA formation that might have occurred as the aerosol was transported across the Pacific was principally associated with the coarse particles.

In summary, the plumes sampled at Whistler between 2 and $5.5 \mathrm{~km}$ show increases in sulphate and coarse particles in combination with reductions in fine particle organic mass. Chemical signatures of both dust and organics are evident in the coarse particles. From 22 April to 26 April, the highest concentrations of coarse particles were measured during the study, both from the aircraft and at Whistler Peak, coincident in transport time with strong dust storms in Mongolia from 15-18 April. The fine particle chemistry in these plumes was dominated by sulphate with relatively little organic material. This is a feature that other studies have attributed to the washout of aerosol particles near the coast of Asia followed by gas and aqueous-phase production of sulphate during transport across the Pacific. It is likely that cloud and precipitation scavenging contributed to the present observations in some way, but the present relationships among sulphate, organic and coarse particles suggest that dust may have played a key role in the reduction of organic material in the fine particles.

\subsection{Mean increases due to Asian transport}

Ozone increases in the range 10-25 ppbv coincided with increases in fine particle sulphate above $2 \mathrm{~km}$. Based simply on comparison of the mean profile of ozone below $2 \mathrm{~km}$ and that above $2 \mathrm{~km}$, and the mean profile excludes three potential cases of direct stratospheric influence, transport during this period increased the mean ozone between 2 and $5 \mathrm{~km}$ by $10 \mathrm{ppbv}$. This estimate agrees with that of Zhang et al. (2008) who interpreted the INTEX-B observations with the GEOS-Chem global chemical transport model and estimated that Asian anthropogenic emissions contributed up to about 9 ppbv to the mean ozone at the Mt. Bachelor Observatory in Oregon.

From the mean profile of sulphate, the increase in fine particle sulphate is estimated three ways: based on a direct comparison of the mean sulphate below and above $2 \mathrm{~km}$, as done for ozone above; relative to the mean organic below and above $2 \mathrm{~km}$; and relative to the mean nitrate below and above $2 \mathrm{~km}$. It is thus estimated that the transport during this period increased the mean fine particle sulphate between $2 \mathrm{~km}$ and $5 \mathrm{~km}$ by $0.2-0.5 \mu \mathrm{g} \mathrm{m}^{-3}$. Sulphate present in coarse particles adds to these numbers. Based on the filter measurements at Whistler Peak, the mean sulphate in coarse particles $(>1 \mu \mathrm{m})$ was about $0.23 \mu \mathrm{g} \mathrm{m}^{-3}$. Assuming that most of this increase was the result of transport, and that assumption is consistent with the observations of coarse particles from the aircraft and at the Peak, then the increase in total sulphate (fine and coarse fractions) is from $0.4-0.7 \mu \mathrm{g} \mathrm{m}^{-3}$. Because the Peak measurements were at $2.2 \mathrm{~km}$ and transport layers were often observed above that level, the estimated total range must be considered a minimum value. van Donkelaar et al. (2008) used GEOS-Chem simulations in combination with the observations from the DC-8 and NCAR C130 as well as the present Cessna observations to estimate that $50 \%$ of the sulphate burden between $1 \mathrm{~km}$ and $5 \mathrm{~km}$ during Intex-B was due to Asian sources. This is consistent with the present results that have a total mean sulphate concentration from $1-5 \mathrm{~km}$ of approximately $1 \mu \mathrm{g} \mathrm{m}^{-3}$. It is estimated here that an increase in the mean total nitrate due to transport was $\geq 0.1 \mu \mathrm{g} \mathrm{m}^{-3}$, and most of this was in the coarse particle fraction.

\subsection{Implications for climate}

As sulphate is amassed in larger particles, its ability to enhance cloud radiative properties through the indirect effect diminishes. Although sulphate particles are well known as good cloud condensation nuclei, larger sulphate particles have higher rates of water uptake. In the base of a cloud, this leads to a reduction of the cloud base supersaturation and inhibits the activation of smaller CCN (e.g. Leaitch et al., 1986). Thus, even though individual particles may be 
better $\mathrm{CCN}$, it is possible that there will be no increase in the number concentration of cloud droplets and even a decrease due to the presence of these larger sulphate particles. On the other hand, the sulphate may become more effective in terms of direct radiative forcing because of the increase in the scattering efficiency as particles get larger further enhanced by the hygroscopic nature of sulphate. Thus, from a liquid cloud perspective, the impact of these plumes is greater on the direct effect than on the indirect effect.

The presence of significant quantities of organic on the dust particles may also alter the direct radiative forcing properties of the dust particles, and the sign may depend on the colour of the organic (e.g. Takahama et al., 2007). Of importance for water resources as well as climate, the addition of organic material deposited on dust particles has been shown to retard the ability of a dust particle to act as ice nuclei (Moehler et al., 2008). Deposition of organics and inorganics to dust leaving Asia could have significant consequences for cloud and rainfall.

\section{Conclusions}

Several cases of aerosol plumes resulting from transPacific transport were observed between $2 \mathrm{~km}$ and $5.3 \mathrm{~km}$ at Whistler, BC from 22 April 2006 to 15 May 2006. The fine particle $(<1 \mu \mathrm{m})$ chemical composition of most of the plumes was dominated by sulphate that ranged from 1$5 \mu \mathrm{g} \mathrm{m}^{-3}$ as measured with a Q-AMS. The coarse particle number concentrations increased in all sulphate plumes between $2 \mathrm{~km}$ and $5 \mathrm{~km}$, and the coarse particle volume was centred between $1 \mu \mathrm{m}$ and $5 \mu \mathrm{m}$, consistent with the size distributions of Asian dust measured in Korea during April 2006 (Lee et al., 2007). The mean sizes of the fine particles in the sulphate plumes were larger in the plumes than elsewhere.

Fine particle organic mass concentrations were relatively low (near detection limit) in most plumes and nominally anticorrelated with the increase in the number concentrations of coarse particles $(>1 \mu \mathrm{m})$ in the plumes. The mean sizes of fine particles were smaller when the fine particle organic mass concentration was larger and dust was absent.

The ion chemistry of the coarse particles sampled at Whistler Peak was dominated by calcium, sodium, nitrate, sulphate and formate. The mean sulphate mass concentration present in the coarse particles was about one half of that measured in the fine particles. Nitrate was almost exclusively in the coarse particles. The mix of calcium and sodium is consistent with the possible origins of the Gobi and Taklamakan deserts. In addition to formate measured in the coarse particles, observations of organic functional groups, from samples collected on the C-130, showed a variety of organic mixtures associated with the coarse particles. Many of the coarse particles collected closer to Whistler contained carbonate, potassium and carboxylates.

Asian plumes reaching Whistler, BC during the INTEX-B study were enhanced in sulphate and coarse particles. Fine particle organic material was not only reduced, but organic compounds were found attached to coarse particles in significant quantities. Suspension of dust with deposited organic material and scavenging of organic particle precursors by dust nearer the anthropogenic sources are possible explanations for the presence of the dust. Any SOA formation during transport from the source regions in Asia across the Pacific had to have been principally taken up on the coarse particles; however, there is no evidence that the coarse organic material was the result of SOA formation.

The means of all profiles indicate that trans-Pacific transport between 2 and $5 \mathrm{~km}$ during this period increased ozone by $10 \mathrm{ppbv}$, fine particle sulphate by $0.2-0.5 \mu \mathrm{g} \mathrm{m}^{-3}$, and particle nitrate by $\geq 0.1 \mu \mathrm{g} \mathrm{m}^{-3}$ (nitrate was almost completely in the coarse fraction).

The presence of the coarse particles of dust during Asian transport acts to accumulate sulphate, nitrate and organic material in larger particles. This will diminish the role these compounds play in indirect radiative forcing, but it may enhance their roles in direct radiative forcing. The addition of organics and inorganics to the coarse particles may also retard the ability of the dust particle to act as ice nuclei leading to further consequences for cloud and rainfall.

Acknowledgements. Rob Buchanan provided professional and tireless piloting of the Cessna during the study. Tragically, Rob lost his life in the crash of the Cessna following the conclusion of the study. Armand Gaudenzi, Dave Halpin and John Deary provided strong technical and logistical support. We thank Stefania Gilardoni and Greg Roberts for collecting the STXM samples, Ald Kilcoyne and ALS for STXM Beamline support, and the mirage Science team and NCAR C-130 crew. The National Science and Engineering Research Council of Canada, Environment Canada and the National Science Foundation (NSF grant atm-0511772) provided financial support. Special thanks go to Juniper Buller, Anton Horvath, the Whistler Ski Patrol and Whistler Blackcomb for their help with this study.

Edited by: H. Singh

\section{References}

Allan, J. D., Bower, K. N., Coe, H., Boudries, H., Jayne, J. T., Canagaratna, M. R., Millet, D. B., Goldstein, A. H., Quinn, P. K., Weber, R. J., and Worsnop, D. R.: Submicron aerosol composition at Trinidad Head, California, during ITCT 2K2: Its relationship with gas phase volatile organic carbon and assessment of instrument performance, J. Geophys. Res.-Atmos., 109(D23), D23S24, doi:10.1029/2003JD004208, 2004.

Allan, J. D., Jimenez, J. L., Williams, P. I., Alfarra, M. R., Bower, K. N., Jayne, J. T., Coe, H., and Worsnop, D. R.: Quantitative sampling using an Aerodyne aerosol mass spectrometer 1. Techniques of data interpretation and error analysis, J. Geophys. Res., 108(D3), 4090-4100, 2003.

Allan, J. D., Delia, A. E., Coe, H., Bower, K. N., Alfarra, M. R., Jimenez, J. L., Middlebrook, A. M., Drewnick, F., Onasch, T. B., Canagaratna, M. R., Jayne, J. T., and Worsnop, D. R.: A generalised method for the extraction of chemically resolved mass spectra from Aerodyne aerosol mass spectrometer data, J. 
Aerosol Sci., 35, 909-922, doi:10.1016/j.jaerosci.2004.02.007, 2004.

Andreae, M. O.: Analysis of aircraft and satellite measurements from the intercontinental chemical transport experiment (INTEX-B) to quantify long-range transport of East Asian Sulfur to Canada, Atmos. Chem Phys. Discuss., 8, 1-41, 2008.

Bluhm, H., Andersson, K., Araki, T., Benzerara, K., Brown, G. E., Dynes, J. J., Ghosal, S., Gilles, M. K., Hansen, H. C., Hemminger, J. C., Hitchcock, A. P., Ketteler, G., Kilcoyne, A. L. D., Kneedler, E., Lawrence, J. R., Leppard, G. G., Majzlam, J., Mun, B. S., Myneni, S. C. B., Nilsson, A., Ogasawara, H., Ogletree, D. F., Pecher, K., Salmeron, M., Shuh, D. K., Tonner, B., Tyliszczak, T., Warwick, T., and Yoon, T. H.: Soft X-ray microscopy and spectroscopy at the molecular environmental science beamline at the Advanced Light source, J. Electron Spectrosc., 150(2-3), 86-104, 2006.

Brock, C. A., Hudson, P. K., Lovejoy, E. R., Sullivan, A., Nowak, J. B., Huey, L. G., Cooper, O. R., Cziczo, D. J., de Gouw, J., Fehsenfeld, F. C., Holloway, J. S., Hübler, G., Lafleur, B. G., Murphy, D. M., Neuman, J. A., Nicks Jr., D. K., Orsini, D. A., Parrish, D. D., Ryerson, T. B., Tanner, D. J., Warneke, C., Weber, R. J., and Wilson, J. C.: Particle characteristics following cloud-modified transport from Asia to North America, J. Geophys. Res., 109, D23S26, doi:10.1029/2003JD004198, 2004.

Broekhuizen, K., Chang, R., Leaitch, W. R., Li, S.-M., and Abbatt, J. P. D.: Closure between measured and modeled cloud condensation nuclei $(\mathrm{CCN})$ using size-resolved aerosol compositions in downtown Toronto, Atmos. Chem. Phys., 5, 6263-6293, 2005, http://www.atmos-chem-phys.net/5/6263/2005/.

Buset, K. C., Evans, G. J., Leaitch, W. R., Brook, J. R., and ToomSauntry, D.: Use of advanced receptor modeling for analysis of an intensive 5-week aerosol sampling campaign, Atmos. Environ., 40, 482-499, 2006.

Carmichael, G. R., Uno, I., Phadnis, M. J., Zhang, Y., and Sunwoo, Y.: Tropospheric ozone production and transport in the springtime in East Asia, J. Geophys. Res.-Atmos., 103, 10 649-10 671, 1998.

Chang, R. Y.-W., Liu, P. S. K., Leaitch, W. R., and Abbatt, J. P. D.: Comparison between measured and predicted CCN concentrations in a semi-rural environment: focus on the organic aerosol fraction, Atmos. Environ., 41, 8172-8182, 2007.

Clarke, A. D., Collins, W. D., Rasch, P. J., Kapustin, V. N., Moore, K., and Howell, S.: Pollution transport on global scales: Measurements and model predictions, J. Geophys. Res., 16, 32 555$32570,2001$.

van Donkelaar, A., Martin, R. V., Leaitch, W. R., Macdonald, A. M., Walker, T. W., Streets, D. G., Zhang, Q., Dunlea, E., Jiminez, J. L., Dibb, J. E., Huey, G., Weber, R., and Andreae, M. O.: Analysis of aircraft and satellite measurements from the Intercontinental Chemical Transport Experiment (INTEX-B) to quantify longrange transport of East Asian sulfur to Canada, Atmos. Chem. Phys., 8, 2999-3014, 2008, http://www.atmos-chem-phys.net/8/2999/2008/.

Dickerson, R. R., Li, C., Li, Z., Marufu, L. T., Stehr, J. W., McClure, B., Krotkov, N., Chen, H., Wang, P., Xia, X., Ban, X., Gong, F., Yuan, J., and Yang, J.: Aircraft observations of dust and pollutants over northeast China: Insight into the meteorological mechanisms of transport, J. Geophys. Res., 112, D24S90, doi:10.1029/2007JD008999, 2007.
Dunlea, E. J., DeCarlo, P. F., Aiken, A. C., Kimmel, J. R., Peltier, R. E., Weber, R. J., Tomlison, J., Collins, D. R., Shinozuka, Y., McNaughton, C. S., Howell, S. G., Clarke, A. D., Emmons, L. K., Apel, E. C., Pfister, G. G., van Donkelaar, A., Martin, R. V., Millet, D. B., Heald, C. L., and Jimenez, J. L.: Evolution of Asian Aerosols during Transpacific Transport in INTEX-B, Atmos. Chem. Phys. Discuss., 8, 15 375-15 461, 2008, http://www.atmos-chem-phys-discuss.net/8/15375/2008/.

Feng, J.: A 3-mode parameterization of below-cloud scavenging of aerosols for use in atmospheric dispersion models, Atmos. Environ., 41, 6808-6822, 2007.

Gong, S.L., Zhang, X. Y., Zhao, T. L., Zhang, X. B., Barrie, L. A., McKendry, I. G., and Zhao, C. S.: A Simulated Climatology of Asian Dust Aerosol and Its Trans-Pacific Transport. Part II: Interannual Variability and Climate Connections, J. Climate, 19, 104-122, 2006.

Hayden, K. L., Macdonald, A. M., Gong, W., Toom-Sauntry, D., Anlauf, K. G., Leithead, A., Li, S.-M., Leaitch, W. R., and Noone, K.: Cloud processing of nitrate, J. Geophys. Res., 113, D18201, doi:10.1029/2007JD009732, 2008.

Harner, T., Shoeib, M., Kozma, M., Gobas, F. A. P. C., and Li, S.-M.: Hexachlorocyclohexanes and endosulfans in urban, rural, and high altitude air samples in the Fraser Valley, British Columbia: evidence for trans-Pacific transport, Environ. Sci. Technol. 39, 724-731, 2005.

Heald, C. L., Jacob, D. J., Park, R. J., Alexander, B., Fairlie, T. D., Yantosca, R. M., and Chu, D. A.: Transpacific transport of Asian anthropogenic aerosols and its impact on surface air quality in the United States, J. Geophys.Res., 111, D14310, doi:10.1029/2005JD006847, 2006.

Holzer, M., McKendry, I. G., and Jaffe, D. A.: Springtime trans-Pacific atmospheric transport from east Asia: a transit-time-pdf approach, J. Geophys. Res., 108, 4708, doi:10.1029/2003JD003558, 2003.

Holzer, M., Hall, T. M., and Stull, R. B.: Seasonality and weatherdriven variability of trans-Pacific transport, J. Geophys. Res., 110, D23103, doi:10.1029/2005JD006261, 2005.

Husar R. B., Tratt, D. M., Schichtel, B. A., Falke, S. R., Li, F., Jaffe, D., Gassó, S., Gill, T., Laulainen, N. S., Lu, F., Reheis, M. C., Chun, Y., Westphal, D., Holben, B. N., Gueymard, C., McKendry, I., Kuring, N., Feldman, G. C., McClain, C., Frouin, R. J., Merrill, J., DuBois, D., Vignola, F., Murayama, T., Nickovic, S., Wilson, W. E., Sassen, K., Sugimoto, N., and Malm, W. C.: The Asian dust events of April 1998, J. Geophys. Res., 106(D16), 18317-18 330, 2001.

Jacob, D., Logan, J. A., and Murti, P. P.: Effect of Rising Asian Emissions on Surface Ozone in the United States, Geophys. Res. Lett., 26, 2175-2178, 1999.

Jacobson, M. Z.: Fundamentals of Atmospheric Modeling, Cambridge Univ. Press, New York, 656 pp., 1999.

Jaffe, D. A., Anderson, T., Covert, D., Kotchenruther, R., Trost, B., Danielson, J., Simpson, W., Berntsen, T., Karlsdottir, S., Blake, D., Harris, J., Carmichael, G., and Uno, I.: Transport of Asian air pollution to North America, Geophys. Res. Lett., 26, 711-714, 1999.

Jaffe, D., McKendry, I., Anderson, T., and Price, H.: Six 'new' episodes of trans-Pacific transport of air pollutants, Atmos. Environ., 37, 391-404, 2003. 
Jaffe, D., Bertschi, I., Jaegle, L., Novelli, P., Reid, J. S., Tanimoto, H., Vingarzan, R., and Westphal, D. L.: Long-range transport of Siberian biomass burning emissions and impact on surface ozone in western North America, Geophys. Res. Lett., 31, L16106, doi:10.1029/2004GL020093, 2004.

Jaffe, D., Prestbo, E., Swartzendruber, P., Weiss-Penzias, P., Kato, S., Takami, A., Hatakeyama, S., and Kajii, Y.: Export of atmospheric mercury from Asia, Atmos. Environ., 39, 3029-3038, 2005.

Jayne, J. T., Leard, D. C., Ahang, X., Davidovits, P., Smith, K. A., Kolb, C. E., and Worsnop, D. R.: Development of an aerosol mass spectrometer for size and composition analysis of submicron particles, Aerosol Sci. Tech., 33, 49-70, 2000.

Junge, C.: Atmospheric Chemistry and Radioactivity, Academic Press, New York, 382 pp., 1963.

Keith, D. W., DeCarolis, J. F., Denkenberger, D. C., Lenschow, D. H., Malyshev, S. L., Pacala, S., and Rasch, P. J.: The influence of large-scale wind-power on global climate, P. Natl. Acad. Sci. USA, 101, 16 115-16 120, 2005.

Kiehl, J. T., Schneider, T. L., Rasch, P. J., Barth, M. C., and Wong, J.: Radiative forcing due to sulfate aerosols from simulations with the National Center for Atmospheric Research Community Climate Model, version 3, J. Geophys. Res., 105, 1441-1457, doi:10.1029/1999JD900495, 2000.

Kilcoyne, A. L. D., Tyliszczak, T., Steele, W. F., Fakra, S., Hitchcock, P., Franck, K., Anderson, E., Harteneck, B., Rightor, E. G., Mitchell, G. E., Hitchcock, A. P., Yang, L., Warwick, T., and Ade, H.: Interferometer-controlled scanning transmission X-ray microscopes at the Advanced Light Source, J. Synchrotron Radiat., 10, 125-136, 2003.

Kline, J., Huebert, B., Howell, S., Blomquist, B., Zhuang, J., Bertram, T., and Carrillo, J.: Aerosol composition and size versus altitude measured from the C-130 during ACE-Asia, J. Geophys. Res., D19S08, doi:10.1029/2004JD004540, 2004.

Huebert, B. J., Bates, T., Russell, P. B., Shi, G., Kim, Y. J., Kawamura, K., Carmichael, G., and Nakajima, T.: An overview of ACE-Asia: Strategies for quantifying the relationships between Asian aerosols and their climatic impacts, J. Geophys. Res., 108(D23), 8633, doi:10.1029/2003JD003550, 2003.

Leaitch, W. R., Strapp, J. W., Isaac, G. A., and Hudson, J. G.: Cloud droplet nucleation and cloud scavenging of aerosol sulphate in polluted atmospheres, Tellus B, 38, 328-344, 1986.

Lee, Y.-G. and Cho, C. H.: Characteristics of aerosol size distribution for a severe Asian dust event observed at Anmyeon, Korea in April 2006, J. Korean Meteor. Soc., 43, 87-96, 2007.

Lim, H.-J., Turpin, B. J., Russell, L., and Bates, T. S.: Organic and elemental carbon measurements during ACE-Asia suggest a longer atmospheric lifetime for elemental carbon, Environ. Sci. Technol., 37, 3055-3061, doi:10.1021/es020988s, 2003.

Liu, P. S. K., Leaitch, W. R., Strapp, J. W., and Wasey, M. A.: Response of Particle Measuring Systems airborne ASASP and PCASP to $\mathrm{NaCl}$ and latex particles, Aerosol Sci. Tech., 16, 8395, 1992.

Liu, M., Westphal, D., Wang, S., Shimizu, A., Sugimoto, N., Zhou, J., and Chen, Y.: A high-resolution numerical study of Asia dust storms of April 2001, J. Geophys. Res., 108(D23), 8653, doi:10.1029/2002JD003178,, 2003.

Lohmann, U., Leaitch, R., Shantz, N., Broekhuizen, K., and Abbatt, J.: How efficient is cloud droplet formation of organic aerosols?,
Geophys. Res. Lett., 31, L05108, doi:10.1029/2003GL018 999, 2004.

McKendry, I. G., Hacker, J. P., Stull, R., Sakiyama, S., Mignacca, D., and Reid, K.: Long range transport of Asian dust to the Lower Fraser Valley, British Columbia, Canada, J. Geophys. Res., 106(D16), 18 361-18 370, 2001.

McKendry, I. G., Strawbridge, K., O’Neill, N., McDonald, A. M., Liu, P., Leaitch, W. R., Anlauf, K., Jaegle, L., Fairlie, D., and Westphal, D.: A Case of Trans-Pacific Transport of Saharan Dust to Western North America, J. Geophys. Res., 112, D01103, doi:10.1029/2006JD007129, 2007.

McKendry, I. G., Macdonald, A. M., Leaitch, W. R., van Donkelaar, A., Zhang, Q., Duck, T., and Martin, R. V.: Trans-Pacific dust events observed at Whistler, British Columbia during INTEX-B, Atmos. Chem. Phys., 8, 6297-6307, 2008,

http://www.atmos-chem-phys.net/8/6297/2008/.

Macdonald, A. M., Anlauf, K. G., Leaitch, W. R., and Liu, P. S. K.: Multi-year chemistry of particles and selected traces gases at the Whistler High Elevation Site, EOS Trans., 87(52), AEB-0719, 2006.

Mayol-Bracero, O L, Santos-Figueroa, G., Morales, F., Colon, L., Carbonaceous Aerosols in African Dust Over the Caribbean, Eos Trans. AGU, 89(53), Fall Meet. Suppl., Abstract A11C-0122, 2008.

Maria, S. F., Russell, L. M., Gilles, M. K., and Myneni, S. C. B.: Organic aerosol growth mechanisms and their climate-forcing implications, Science, 306(5703), 1921-1924, 2004.

Maria, S. F., Russell, L. M., Turpin, B. J., Porcja, R. J., Campos, T. L., Weber, R. J., and Huebert, B. J.: Source signatures of carbon monoxide and organic functional groups in Asian Pacific Regional Aerosol Characterization Experiment (ACE-Asia) submicron aerosol types, J. Geophys. Res.-Atmos., 108, 2003.

Matthew, B. M., Onasch, T. B., and Middlebrook, A. M.: Collection efficiencies in an Aerodyne Aerosol Mass Spectrometer as a function of particle phase for laboratory generated aerosols, Aerosol Sci. Tech., 42(11), 884-898, doi:10.1080/02786820802356797, 2008.

Moehler, O., Benz, S., Saathoff, H., Schnaiter, M., Wagner, R., Schneider, J., Walter, S., Ebert, V., and Wagner, S.: The effect of organic coating on the heterogeneous ice nucleation efficiency of mineral dust aerosols, Environ. Res. Lett., 3, 025007 (8pp) doi:10.1088/1748-9326/3/2/025007, 2008.

Papayannis, A., Zhang, H. Q., Amiridis, V., Ju, H. B., Chourdakis, G., Georgoussis, G., Pérez, C., Chen, H. B., Goloub, P., Mamouri, R. E., Kazadzis, S., Paronis, D., Tsaknakis, G., and Baldasano, J. M.: Extraordinary dust event over Beijing, China, during April 2006: Lidar, Sun photometric, satellite observations and model validation, Geophys. Res. Lett., 34, L07806, doi:10.1029/2006GL029125, 2007.

Phinney, L., Leaitch, W. R., Lohmann, U., Boudries, H., ToomSauntry, D., Sharma, S., and Shantz, N.: Characterization of Aerosol Over the Sub-arctic NE Pacific During SERIES, DeepSea Res. Pt. II, 53, 2410-2433, 2006.

Prospero, J. M., Ginoux, P., Torres, O., Nicholson, S., and Gill, T.: Environmental characterization of global sources of atmospheric soil dust identified with the NIMBUS7 Total Ozone Mapping Spectrometer (TOMS) absorbing aerosol product, Rev. Geophys., 40, 1002, doi:10.1029/2000RG000095, 2002. 
Rasch, P. J., Collins, W. D., and Eaton, B. E.: Understanding the Indian Ocean Experiment (INDOEX) aerosol distributions with an aerosol assimilation, J. Geophys. Res., 106, 7337-7355, 2001.

Rasch, P. J., Barth, M. C., Kiehl, J. T., Schwartz, S. E., and Benkovitz, C. M.: A description of the global sulfur cycle and its controlling processes in the National Center for Atmospheric Research Community Climate Model, Version 3, J. Geophys. Res., 105, 1367-1385, 2000.

Rupakheti, M., Leaitch, W. R., Lohmann, U., Hayden, K., Brickell, P., Lu, G., Li, S.-M., Toom-Sauntry, D., Bottenheim, J. W., Brook, J. R., Vet, R., Jayne, J. T., and Worsnop, D. R.: An intensive study of the size and composition of submicron atmospheric aerosols at a rural site in Ontario, Canada, Aerosol Sci. Tech., 39, 722-736, 2005.

Russell, L. M., Maria, S. F., and Myneni, S. C. B.: Mapping organic coatings on atmospheric particles, Geophys. Res. Lett., 29(16), 1779, doi:10.1029/2002GL014874, 2002.

Seigneur, C., Vijayaraghavan, K., Lohman, K., Karamchandani, P., and Scott, C.: Global source attribution for mercury deposition in the United States, Environ. Sci. Technol., 38, 555-569, 2004.

Singh, H. B., Brune, W. H., Crawford, J. H., Flocke, F., and Jacob, D. J.: Chemistry and transport of pollution over the Gulf of Mexico and the Pacific: spring 2006 INTEX-B campaign overview and first results, Atmos. Chem. Phys., 9, 2301-2318, 2009,

http://www.atmos-chem-phys.net/9/2301/2009/.

Shantz, N. C., Leaitch, W. R., Phinney, L., Mozurkewich, M., and Toom-Sauntry, D.: The effect of organic compounds on the growth rate of cloud droplets in marine and forest settings, Atmos. Chem. Phys., 8, 5869-5887, 2008,

http://www.atmos-chem-phys.net/8/5869/2008/.

Stohl, A., Eckhardt, S., Forster, C., James, P., and Spichtinger, N.: On the pathways and timescales of intercontinental air pollution transport, J. Geophys. Res., 107, 4684, doi:10.1029/2001JD001396, 2002.

Song, C.-H. and Carmichael, G. R.: The aging process of naturally emitted aerosol (sea-salt and mineral aerosol) during long range transport, Atmos. Envrion., 33, 2203-2218, 1999.

Streets, D. G. and Waldhoff, S. T.: Present and future emissions of air pollutants in China: SO2, NOx, and CO, Atmos. Environ., 34, 363-374, 2000.

Strapp, J. W., Leaitch, W. R., and Liu, P. S. K.: Hydrated and dried aerosol size distribution measurements from the Particle Measuring Systems FSSP-300 probe and the de-iced PCASP-100X probe, J. Atmos. Ocean. Tech., 9, 548-555, 1992.

Sullivan, R. C. and Prather, K. A.: Investigations of the Diurnal Cycle and Mixing State of Oxalic Acid in Individual Particles in Asian Aerosol Outflow, Environ. Sci. Technol., 41, 8062-8069, 2007.

Sun, Y., Zhang, Q., Macdonald, A. M., Hayden, K., Li, S. M., Liggio, J., Liu, P. S. K., Anlauf, K. G., Leaitch, W. R., Steffen, A., Cubison, M., Worsnop, D. R., van Donkelaar, A., and Martin, R. V.: Size-resolved aerosol chemistry on Whistler Mountain, Canada with a high-resolution aerosol mass spectrometer during INTEX-B, Atmos. Chem. Phys., 9, 3095-3111, 2009, http://www.atmos-chem-phys.net/9/3095/2009/.

Takahama, S., Gilardonia, S., Russell, L. M., and Kilcoyne, A. L. D.: Classification of multiple types of organic carbon composition in atmospheric particles by scanning transmission x-ray microscopy analysis, Atmos. Environ., 41(40), 9435-9451, 2007.
Takahama, S., Gilardoni, S., and Russell, L. M.: Single-Particle Oxidation-State and Morphology of Atmospheric Iron Aerosols, J. Geophys. Res., 113, D22202, doi:10.1029/2008JD009810, 2008.

Thulasiraman, S., O’Neill, N. T., Royer, A., Holben, B. N., Westphal, D. L., and McArthur, L. J. B.: Sunphotometric observations of the 2001 Asian dust storm over Canada and the U.S., Geophys. Res. Lett., 29(8), 1255, doi:10.1029/2001GL014188, 2002.

Tratt, D. M., Frouin, R. J., and Westphal, D. L.: The April 1998 Asian dust event: A Southern California Perspective, J. Geophys. Res., 106, 18 371-18 379, 2001.

Uematsu, M., Duce, R. A., Prospero, J. M., Chen, L., Merrill, J. T., and McDonald, R. L.: Transport of mineral aerosol from Asia over the North Pacific Ocean, J. Geophys. Res., 88, 5343-5352, 1983.

Wang, Y., Zhuang, G., Chen, S., An, Z., and Zheng, A.: Characteristics and sources of formic, acetic and oxalic acids in PM2.5 and PM10 aerosols in Beijing, China, Atmos. Res., 84, 169-181, 2007.

Wang, J., Lee, Y.-N., Daum, P. H., Jayne, J., and Alexander, M. L.: Effects of aerosol organics on cloud condensation nucleus (CCN) concentration and first indirect aerosol effect, Atmos. Chem. Phys., 8, 6325-6339, 2008,

http://www.atmos-chem-phys.net/8/6325/2008/.

Weiss-Penzias, P., Jaffe, D., Swartzendruber, P., Hafner, W., Chand, D., and Prestbo, E.: Quantifying Asian and biomass burning sources of mercury using the $\mathrm{Hg} / \mathrm{CO}$ ratio in pollution plumes observed at the Mount Bachelor observatory, Atmos. Environ., 41(21), 4366-4379, doi:10.1016/j.atmosenv.2007.01.058, 2007.

De Wekker, S. F. J., Steyn, D. G., and Nyeki, S.: A comparison of aerosol layer- and convective boundary layer structure over a mountain range during STAAARTE '97, Bound.-Lay. Meteorol., 113, 249-271, 2004.

Zhao, T. L., Gong, S. L., Zhang, X. Y., Blanchet, J.-P., McKendry, I. G., and Zhou, Z. J.: A Simulated Climatology of Asian Dust Aerosol and Its Trans-Pacific Transport. Part I: Mean Climate and Validatio, J. Climate, 19, 88 pp., 2006.

Yuan, H., Zhuang, G., Rahn, K. A., Zhang, X., and Li, Y.: Composition and mixing of individual particles in dust and nondust conditions of north China, spring 2002, J. Geophys. Res., 111, D20208, doi:10.1029/2005JD006478, 2006.

Zhang, X., Zhuang, G., and Yuan, H.: The dried salt-lakes saline soils sources of the dust storm in Beijing - the individual particles analysis and XPS surface structure analysis, China Environmental Science, 24(5), 533-537, 2004.

Zhang, L., Jacob, D. J., Boersma, K. F., Jaffe, D. A., Olson, J. R., Bowman, K. W., Worden, J. R., Thompson, A. M., Avery, M. A., Cohen, R. C., Dibb, J. E., Flocke, F. M., Fuelberg, H. E., Huey, L. G., McMillan, W. W., Singh, H. B., and Weinheimer, A. J.: Transpacific transport of ozone pollution and the effect of recent Asian emission increases on air quality in North America: an integrated analysis using satellite, aircraft, ozonesonde, and surface observations, Atmos. Chem. Phys., 8, 6117-6136, 2008, http://www.atmos-chem-phys.net/8/6117/2008/.

Zhang, Q., Canagaratna, M. R., Jayne, J. T., Worsnop, D. R., and Jimenez, J. L.: Time- and Size-Resolved Chemical Composition of Submicron Particles in Pittsburgh: Implications for Aerosol Sources and Processes, J. Geophys. Res.-Atmos., 110, D07S09, doi:10.1029/2004JD004649, 2005. 